1. Comparison of 4DVAR and EnKF State Estimates and Forecasts in the Gulf

\title{
of Mexico
}

Ganesh Gopalakrishnan*

${ }_{4}$ Climate, Atmospheric Science and Physical Oceanography, Scripps Institution of Oceanography, USA.

King Abdullah University of Science and Technology, Kingdom of Saudi Arabia.

Climate, Atmospheric Science and Physical Oceanography, Scripps Institution of Oceanography, USA. Marine Physical Laboratory, Scripps Institution of Oceanography, USA.

${ }_{13}^{*}$ Corresponding author address: Ganesh Gopalakrishnan.

${ }_{14}$ E-mail: ggopalakrishnan@ucsd.edu 
ABSTRACT

15 


\section{Abstract}

An experiment is conducted to compare four-dimensional variational (4DVAR) and ensemble Kalman filter (EnKF) assimilation systems and their predictability in the Gulf of Mexico (GoM) using the Massachusetts Institute of Technology general circulation model (MITgcm). The quality of the ocean state estimates, forecasts, and the contribution of ensemble prediction are evaluated. The MITgcm - Estimating the Circulation and Climate of the Ocean (ECCO) 4DVAR (MITgcm-ECCO) and the MITgcm - Data Assimilation Research Testbed (DART) EnKF (MITgcm-DART) systems were used to compute two month hindcasts (March - April, 2010) by assimilating satellite-derived along-track sea-surface height ( $\mathrm{SSH})$ and gridded sea-surface temperature (SST) observations. The estimates from both methods at the end of the hindcast period were then used to initialize forecasts for two months (May - June, 2010). This period was selected because a Loop Current (LC) eddy (Eddy Franklin: Eddy-F) detachment event occurred at the end of May 2010, immediately after the Deepwater Horizon (DwH) oil spill. Despite some differences between the setups, both systems produce analyses and forecasts of comparable quality and both solutions significantly outperformed model persistence. A reference forecast initialized from the $1 / 12^{\circ} \mathrm{HYCOM} / \mathrm{NCODA}$ global analysis also performed well. The EnKF experiments for sensitivity to filter parameters showed enhanced predictability when using more ensemble members and stronger covariance localization, but not for larger inflation. The EnKF experiments varying the number of assimilation cycles showed enhanced short-term (long-term) predictability with fewer (more) assimilation cycles. Additional hindcast and forecast experiments at other times of significant LC evolution showed mixed performances of both systems that strongly depends on the background state of the GoM circulation. The present work demonstrates a practical application of both assimilation methods for the GoM and compares them in a limited number of realiza- 
tions. The overall conclusion showing improved short-term (long-term) predictability for EnKF (4DVAR) carries an important caveat that the results from this study are specific to a few 4DVAR and EnKF LC eddy separation experiments in the GoM and cannot be generalized to conclude the relative performances of both methods, especially in other applications. However, some of the concepts and methods should carry over to other applications.

\section{Introduction}

Analyzing and predicting the ocean state has long been an important goal of the scientific community. Even though ocean observing platforms have witnessed tremendous developments in the last decade, oceanic observations are still sparse and intermittent compared to the scales needed to completely represent the ocean variability. Numerical models are routinely used to supply extra information in the form of dynamic and kinematic constraints, but also bring uncertainties due to poorly known inputs and parameters, limited resolution, approximate parameterizations of unresolved physics, and numerics. Efficient combination of numerical models and observations using the framework of data assimilation (DA) is now recognized as the most effective way to forecast the state of the ocean (Ghil and Malanotte-Rizzoli 1991; Wunsch 1996; Edwards et al. 2015).

DA methods exploit the model dynamics as an interpolator of the data in space and time. By construction, they also readily provide a dynamical forecasting system that is updated by the observations. The theoretical framework of DA for oceanic problems is now well established and two separate directions are usually followed; the deterministic variational approach and the statistical filtering approach (Edwards et al. 2015). Variational methods seek the model trajectory that best fits the observations by minimizing an objective function measuring the discrepancy between the model predictions and observations by adjusting uncertain model parameters. Adjoint methods can be used to compute the gradients needed for the optimization of the objective function (Le Dimet 
and Talagrand 1986). Statistical methods proceed by sequentially updating a model prediction every time new observations are available, taking into account their respective uncertainties. Ensemble Kalman filters (EnKFs), which are Monte Carlo implementations of the celebrated Kalman filter, are now widely used in the ocean community (Hoteit et al. 2002; Tippett et al. 2003). The readers are referred to a detailed review paper by Edwards et al. (2015) (and references therein) on the historical developments of variational and sequential methods and recent advances in ensemble and four-dimensional variational approaches in the context of regional ocean assimilation systems.

DA is used to improve model representations of the ocean circulation at global and regional scales, to test formal hypotheses in models, and to assess observing systems. Examples of major ocean DA systems include the US NAVOCEANO forecasting system (Smedstad et al. 2003), the Mediterranean Forecasting System (MFS) (Pinardi et al. 2003), the French MERCATOR system (Brasseur et al. 2005), the Meteorological Research Institute Multivariate Ocean Variational Estimation (MOVE) system (Usui et al. 2006), the Hybrid Coordinate Ocean Model (HYCOM) Nowcast/Forecast system (Chassignet et al. 2007), the Australian Bluelink Ocean Data Assimilation System (BODAS) (Oke et al. 2008). All these systems are based on so-called threedimensional DA methods (Optimal Interpolation - OI and three-dimensional variation - 3DVAR), which are simplified versions of the Kalman filter (KF) operating with static error covariance matrices. With progress in computing resources, transition to more advanced four-dimensional data assimilation systems based on Four-Dimensional Variational (4DVAR) methods and the Ensemble Kalman filters (EnKFs) methods is underway. Examples of the ongoing efforts to build advanced 4DVAR assimilation systems include the Nucleus for European Modelling of the Ocean (NEMO) incremental variational system based on the observation-space formulation of the weak constraint 4DVAR (Mogensen et al. 2009), the Regional Ocean Modeling System (ROMS) 4DVAR with 
its three variants: incremental strong constraint 4DVAR (I4DVAR), a dual formulation based on a physical-space statistical analysis system (4DVAR-PSAS), and a dual formulation representerbased variant of 4DVAR (R4DVAR) (Moore et al. 2011c,a,b), and the Estimating the Circulation and the Climate of the Ocean (ECCO) system, which uses the Massachusetts Institute of Technology general circulation model (MITgcm), and is enabled to adjust various model parameters and inputs ("model controls") (Stammer et al. 2002; Wunsch and Heimbach 2007; Forget et al. 2015). Several other ocean data assimilation projects are designing their assimilation systems based on various flavors of EnKFs. Some examples are the Towards an Operational Prediction system for the North Atlantic European coastal Zones (TOPAZ) (Bertino et al. 2008), the European COastal sea and Operational observing and Prediction system (ECCOP) (Nerger et al. 2005), the POSEIDON monitoring, forecasting and information system for the Greek Seas (Korres et al. 2010), and the global ocean DA system at the Global Modeling and Assimilation Office (GMAO) (Keppenne et al. 2005), and the Red Sea ocean assimilation system (Toye et al. 2017).

The MITgcm-ECCO assimilation system has focused on providing multi-decadal global ocean reanalyses, e.g. Köhl et al. (2007), Wunsch and Heimbach (2007), and more recently Forget et al. (2015). It was also successfully used by Hoteit et al. (2005); Gebbie et al. (2006); Mazloff et al. (2010); Hoteit et al. (2009, 2010) for regional, eddy-permitting configurations. Recently, the MITgcm-ECCO system has been configured for the Gulf of Mexico (GoM) region by Gopalakrishnan et al. (2013b) to produce short-term (two month) analysis and forecasts for the Loop Current (LC) circulation in the GoM.

To equip the MITgcm with more predictive capabilities, the ensemble Data Assimilation Research Testbed (DART) package (Anderson et al. 2009), has been implemented with the MITgcm (Hoteit et al. 2013). DART is a portable software facility employing multiple stochastic and deterministic EnKFs. It has been developed at the National Center of Atmospheric Research (NCAR) 
and is now used for research and operational weather forecasting problems (Zubrow et al. (2008); Aksoy et al. (2009); Dowell and Wicker (2009), to cite but a few). The MITgcm-DART system has been tested for LC predictability in the GoM by Hoteit et al. (2013), and for predicting the circulation of the Red Sea by Toye et al. (2017).

The objectives of these two MITgcm-based assimilation systems, MITgcm-ECCO and MITgcmDART, are related although their technical approaches differ. One important difference between a variational and an EnKF DA system is that EnKFs provide an efficient dynamical approach to update approximate forecast uncertainties (or background) in time, making them more suitable for forecasting than 4DVAR (Lorenc 2003). Another practical advantage is that 4DVAR requires the implementation of the model adjoint while an EnKF does not, and so is called "non-intrusive" (Lorenc 2003). However, unlike 4DVAR, the EnKF solution is not necessarily consistent with the (non-linear) dynamics of the system, making it less suitable to study ocean dynamical balances (Houtekamer and Mitchell 2005). This is further amplified by the need for adhoc techniques (e.g. localization and inflation) to mitigate rank-deficiency of ensemble covariances due to the use of small ensembles (Song et al. 2010).

This study demonstrates the practical application of both 4DVAR and EnKF methods for the GoM, and is the first attempt to quantitatively compare the two DA methods for regional ocean state estimation and prediction. In the weather forecasting community, several studies have reported comparisons of variational and sequential DA approaches for different weather-related applications, although few of them were based on realistic model hindcasting and forecasting systems. Zhang et al. (2011) compared EnKF against both 3DVAR and 4DVAR methods with the Weather Research and Forecasting (WRF) model for a warm season over the contiguous United States. The EnKF and 4DVAR forecast errors were comparable at 12-36h lead times and both were substantially smaller than the 3DVAR forecast errors, whereas the longer lead time fore- 
cast errors from EnKF were smaller than the 4DVAR/3DVAR forecasts. Lorenc (2003) compared EnKF with 4DVAR for a medium-range mesoscale numerical weather prediction (NWP) system, and found EnKF is less suitable for uncertainty in a wide range of scales and may not use highresolution satellite data as effectively as 4DVAR, and suggested a EnKF-4DVAR hybrid method. Yang et al. (2009) compared the Local ensemble transform Kalman Filter (LETKF) with 3DVAR and 4DVAR schemes in a quasi-geostrophic channel model and found that, LETKF and 4DVAR solutions are superior to 3DVAR solutions. The LETKF solutions, which account for the flowdependent background error covariance, are more accurate than 4DVAR within a $12 \mathrm{~h}$ window, while 4DVAR solutions greatly benefit from longer assimilation windows. Another comparison study between LETKF and 4DVAR with the experimental operational system at the Japanese Meteorological Agency (JMA) by Miyoshi et al. (2010) reported that overall performance of both methods are essentially comparable. Whitaker et al. (2009) compared 4DVAR and 3DVAR systems with ensemble-based data assimilation (EnsDA) in a surface-only, observing system experiment. They found that 4DVAR and EnsDA solutions were comparable, that both were superior to 3DVAR solutions, and that the EnsDA system provided useful estimates of analysis error. An intercomparison study of five different variational and EnKF systems for the Environmental Canada was reported by Buehner et al. (2010) in the context of global deterministic NWP. The forecast quality from that study showed varied skill depending on the flow-dependent EnKF error covariances. The readers are directed to the special collection of papers on intercomparison of both methods at http://journals.ametsoc.org/page/Ensemble_Kalman_Filter.

The main focus of this work is to compare MITgcm-ECCO and MITgcm-DART for eddypermitting, estimation and prediction of the circulation of the GoM. To produce GoM state estimates, both satellite-derived along-track sea-surface height (SSH) and gridded sea-surface temperature (SST) data are assimilated over a period of two months (March - April, 2010). These 
are then used to initialize a forecast for two months (May - June, 2010) starting from the end of the assimilation period. The performance of the assimilation methods are analyzed by computing model-observation root-mean-square-difference $(r m s d)$ for the satellite SSH and SST data during both the hindcast and forecast periods. Model forecasts from both assimilation methods are also compared against independent Spray glider (Sherman et al. 2001; Rudnick et al. 2004) measurements of temperature and salinity profiles taken in the northern GoM continental shelf waters. Forecasts from the 4DVAR optimized state, the EnKF ensemble members, and the EnKF ensemble mean analysis are compared over the two month period during a LC eddy (Eddy-F) detachment event in late May 2010. Sensitivity experiments with respect to various MITgcm-DART EnKF parameters, such as the ensemble size, localization length scale, covariance inflation factor, and number of assimilation cycles (hindcast period) are also conducted and their respective impact on the system predictability is assessed. Additionally, MITgcm-ECCO and MITgcm-DART are compared for time periods other than 2010 , testing predictability of the system for various LC eddy separation events in the GoM during 2006 (Eddy Yankee), 2013, and 2014 (Eddy Kraken).

\section{Model Configuration and Observations}

\section{a. MITgcm - Intra-Americas Seas (MITgcm-IAS) Model}

The MITgcm Intra-Americas Seas (MITgcm-IAS) model is a regional implementation of the MITgcm (Marshall et al. 1997). The setup of the model, including model initial conditions, open boundary conditions, and atmospheric forcings, is the same as the one implemented in Gopalakrishnan et al. (2013a), and is summarized in Tables 1 and 2. A more detailed description and a forward model evaluation against observations can be found in Gopalakrishnan et al. (2013a). 


\section{b. Observations}

The observations used in this study are the same as assimilated in Gopalakrishnan et al. (2013b) and are outlined in Table 3. The following description of observations is derived from Gopalakrishnan et al. (2013b) with minor modifications to explain how these are assimilated into MITgcmECCO and MITgcm-DART systems.

SSH anomalies were obtained from the Radar Altimetry Database System (RADS, http: //rads.tudelft.nl/rads/index.shtml). For MITgcm-ECCO, the along-track observations from three satellites: Jason-1 (J1), Jason-2 (J2), and Envisat (N1) with respect to the time-mean dynamic ocean topography (MDT), calculated from the difference between the Danish National Space Center Mean Sea Surface 2008 (DNSCMSS08) and Earth Gravity Model 2008 (EGM08): DNSCMSS08-EGM08 (Andersen and Knudsen 2009; Pavlis et al. 2012), were computed over each day and spatially bin-averaged onto the model grid. For MITgcm-DART, along-track SSH observations from the same three satellites were converted into absolute SSH signal by adding the MDT (DNSCMSS08-EGM08), and were sampled at observation locations within the assimilation window of 3 days ( \pm 1.5 day from the analysis time). Since the current configuration of the MITgcm-IAS model did not include tidal or atmospheric pressure forcing, tidal corrections and inverted barometer correction were applied to the along-track SSH observations.

The SST data were obtained from the daily optimally interpolated product derived from the Tropical Rainfall Measuring Mission's (TRMM) Microwave Imager (TMI) and the Advanced Microwave Scanning Radiometer for the Earth Observing System (AMSR-E) instruments produced by Remote Sensing Systems Inc. (http://www.remss.com/) on a $0.25^{\circ}$ longitude $\times 0.25^{\circ}$ latitude grid. For MITgcm-ECCO, the daily gridded SST data were spatially interpolated onto the model grid $\left(0.10^{\circ}\right.$ longitude $\times 0.10^{\circ}$ latitude grid $)$ prior to assimilation for computational conve- 
nience. For MITgcm-DART, the daily gridded SST data were sampled at the observation grid resolution of $0.25^{\circ}$ longitude $\times 0.25^{\circ}$ latitude, and were averaged over the 3-day assimilation window ( \pm 1.5 day from the analysis time).

The time mean of the TMI/AMSR-E SST data for March 1 - April 29, 2010 is shown in Figure 1a. Superposed satellite ground tracks from three satellites: Jason-1 (J1), Jason-2 (J2) and Envisat (N1) for the same period are shown in Figure 1b. In order to ensure the quality of SSH and SST data and to account for expected model representational error, observations near the coast (at water depth $<500 \mathrm{~m})$ were not used for assimilation.

Besides the above observations which are used in the state estimates, temperature and salinity observations from a glider trajectory in the GoM were used for independent data comparison with model forecasts. The SIO and the Woods Hole Oceanographic Institution (WHOI) deployed a Spray glider (Sherman et al. 2001; Rudnick et al. 2004) in the northern GoM continental shelf waters during June 2010 as part of the DwH oil spill monitoring. The glider temperature and salinity data, spanning from the surface to a depth of $500 \mathrm{~m}$, were binned every 6 hours. The glider trajectory is marked by magenta circles in Figure 1a (top panel). Although these glider observations only sampled northern shelf-slope waters which are not representative of the central GoM/LC water masses, they are used here as independent data for assessing the forecasts of subsurface water properties from both methods, to verify that adjustments to the LC state do not degrade the estimate elsewhere.

\section{c. Observation Uncertainty Covariances}

The prior estimates of observation uncertainties for both SSH and SST are dominated by model representational errors which include expected error in the atmospheric forcing values that determine the mixed-layer depth (and thus affect modeled SST), coarse time resolution of atmospheric 
forcing, and expected errors in the parameterizations of mixing in the model, all of which affect the model mixed-layer physics.

\section{1) MITGCM-ECCO}

$\mathrm{SSH}$ : The MITgcm-ECCO is capable of isolating the uncertainties associated with the timeindependent geoid from the generally smaller uncertainties in the anomalies, and the model SSH time mean and anomalies were separately fit to the observed along-track SSH time mean and anomaly with different uncertainties in the two cost functions. The SSH anomaly uncertainty was assumed to be spatially-invariant, at $5 \mathrm{~cm}$ for Jason-1 (J1), Jason-2 (J2), and $10 \mathrm{~cm}$ for Envisat (N1) and ERS-2 (E2), and the geoid uncertainty is also assumed to be spatially-invariant at $10 \mathrm{~cm}$.

SST: The SST data uncertainty was set at 5 times the standard deviation (over time) of the modeled SST over five-years (forward model solution for 2004 - 2008 taken from Gopalakrishnan et al. (2013a)), and were limited to be between $10^{\circ} \mathrm{C}$ in the deep central $\mathrm{GoM}$ to $50^{\circ} \mathrm{C}$ in the shallow coastal waters. Since the gridded SST data were spatially interpolated to model grid points for computational convenience, relatively high SST observational uncertainty, especially near the coast, is used to account for the redundant interpolated observations and model representational error, which are expected to be high near the coast in relatively shallow water. The detailed description of the observation uncertainty covariances, same as the one used in this study for the MITgcm-ECCO system, can be found in Gopalakrishnan et al. (2013b).

\section{2) MITGCM-DART}

$S S H$ : The MITgcm-DART system assimilates absolute (anomaly + MDT) along-track SSH, and the observation error for SSH was assumed to be the same as for the MITgcm-ECCO anomalies: spatially-invariant, at $5 \mathrm{~cm}$ for $\mathrm{J} 1$ and $\mathrm{J} 2$, and $10 \mathrm{~cm}$ for $\mathrm{N} 1$ and $\mathrm{E} 2$. 
SST: The MITgcm-DART assimilates gridded SST data at observation locations, and the observation error for SST is assumed to be spatially-invariant at $10^{\circ} \mathrm{C}$. This high SST error is assumed to include model representational error in the mixed-layer physics and to make it consistent with the prior estimates of SST error in MITgcm-ECCO.

\section{d. Background Uncertainty Covariances}

The background uncertainty covariances for both MITgcm-ECCO 4DVAR and MITgcm-DART EnKF systems are based on the model variability over the five-year forward model simulation for the period 2004 - 2008 (Gopalakrishnan et al. 2013a). These uncertainties were treated differently depending on the assimilation systems.

\section{1) MITGCM-ECCO}

For the MITgcm-ECCO 4DVAR, the background uncertainty covariances for the model initial temperature and salinity controls were computed from the standard deviation (over time) of the model variability over five-years (forward model solution for 2004 - 2008 taken from Gopalakrishnan et al. (2013a)). These background error covariances were first multiplied by $\sqrt{\frac{\mathrm{d} z \min }{\mathrm{d} z}}\left(\mathrm{~d} z_{\text {min }}\right.$ is minimum depth level thickness and $\mathrm{d} z$ is vertical $z$-level thickness) to compensate for the larger raw sensitivities at depth levels with large $z$-level thickness. The MITgcm-ECCO 4DVAR formulation assumes the background uncertainty covariances $(\mathbf{Q}$, Equation 1 in Gopalakrishnan et al. (2013b)) to be diagonal, meaning that the background uncertainty was assumed to be independent point-to-point. To keep the adjustment fields appropriately smooth, the MITgcm-ECCO 4DVAR system enforces 2D and 3D smoothness of control variables following Weaver et al. (2003); Forget (2009); Hoteit et al. (2010). We used a decorrelation scale of $50 \mathrm{~km}$ for the smoothed controls in the horizontal, and of $10 \mathrm{~m}$ in the vertical (the vertical scale was set small so that each level was 
independent). In order to account for the diagonality assumption and for the smoothing scales, the background uncertainty covariances were increased, by a factor of about 14 for the surface levels (100 km horizontal scale corresponds to 10 grid points of $0.10^{\circ}$ longitude $\times 0.10^{\circ}$ latitude model grid, and $10 \mathrm{~m}$ in the surface consists of two depth levels, which corresponds to a factor of $\sqrt{200}$ ), and by a factor of about 10 for the depth levels below. These increased background uncertainty covariances also account for the model representational errors, especially near the surface, such as errors due to bad atmospheric forcing or mixed layer physics.

This amplification of background error covariances is required in order to make sufficient adjustments to the initial condition controls to allow the model to fit the observations. Sensitivity experiments scaling these uncertainties by factors of two did not have much effect on the solutions, and the adjustments to temperature and salinity initial condition controls were not overly large near the surface (not shown). Adjustments in depth (greater than $3000 \mathrm{~m}$ ) were discouraged by low prior variance, since they were not expected to be realistic. A detailed description of the background uncertainty covariances used in this study can be found in Gopalakrishnan et al. (2013b) which used the same MITgcm-ECCO 4DVAR system.

\section{2) MITGCM-DART}

The MITgcm-DART EnKF assimilation system starts from an initial ensemble of state vectors that is meant to represent the uncertainties around the initial state estimate. For the MITgcmDART EnKF, the background error covariances was estimated from an Empirical Orthogonal Function (EOF) analysis of a large set of model realizations (taken from a forward model solution for 2004 - 2008 from Gopalakrishnan et al. (2013a), which was also used in the MITgcmECCO 4DVAR background uncertainty covariances). The three-dimensional, multi-variate EOFs are computed from the historic simulation without removing the seasonality, which is assumed to 
be relatively low in this region. The percentage of variance explained by the first five EOFs are EOF-1) 22, EOF-2) 10, EOF-3) 7, EOF-4) 6, EOF-5) 4, and the cumulative variance explained by the first 50 EOFs is about $90 \%$. This background uncertainty covariance is not diagonal by virtue of multi-variate EOFs. A detailed description of generation of the filter initial ensemble for the MITgcm-DART EnKF system can be found in Hoteit et al. (2013).

\section{MITgcm-IAS 4DVAR Framework}

The MITgcm-IAS 4DVAR assimilation is based on the ECCO system (Stammer et al. 2002). Although the MITgcm-IAS model and the MITgcm-ECCO 4DVAR state estimation method used in this study are the same as implemented in Gopalakrishnan et al. (2013b), the 4DVAR assimilation experiment in this study were re-done with following changes to make it more comparable to the MITgcm-DART EnKF as described below: 1) The length of the assimilation window was reduced to 60 days from 61 in the Gopalakrishnan et al. (2013b) to match the MITgcm-DART experiment. 2) Even though the MITgcm-ECCO system enables a variety of control parameters, here we only adjust the model initial conditions for temperature and salinity for a direct and fair comparison with the MITgcm-DART results, while the Gopalakrishnan et al. (2013b) also included open boundary and atmospheric forcing controls. A detailed description of the state estimation procedure, including control variables, cost functions for observations, model background uncertainty covariances, observation uncertainty covariances, and the iterative optimization can be found in Gopalakrishnan et al. (2013b).

\section{a. MITgcm-IAS 4DVAR State Estimation Experiment}

The satellite-derived along-track SSH, separated into temporal mean and anomalies, and gridded SST data were assimilated using MITgcm-ECCO over an assimilation window of two-months: 
March 1 - April 29, 2010. The state estimation optimizes the model trajectory by adjusting the model control variables, which in this case are model initial conditions for temperature and salinity. The model initialization for the MITgcm-ECCO control simulation and the treatment of the viscosity and diffusivity parameters in the MITgem-ECCO forward and adjoint model simulations are the same as in Gopalakrishnan et al. (2013b), and the following description is derived from there. The control model simulation (MIT-C) is the forward model solution from iteration 1, which uses initial conditions and boundary conditions from assimilated HYCOM/NCODA $1 / 12^{\circ}$ global daily analysis (http://hycom.org/dataserver/glb-analysis), atmospheric forcing from National Centers for Environmental Prediction/National Center for Atmospheric Research Reanalysis-1 (NCEP/NCAR-R1) (Kalnay et al. 1996) surface fluxes and winds, and monthly climatological run-off fluxes (freshwater) from ECCO global model state estimate. The initial conditions, open boundary conditions, and atmospheric forcing for the MIT-C are the background and "first-guess" for the state estimation.

The MITgcm-ECCO adjoint model simulation used increased horizontal diffusivity and viscosity terms (second order terms were increased by a factor of 10 and fourth order terms were increased by a factor of 5 of the forward model simulation, refer Table 1), with the KPP mixing parameterization turned off (Hoteit et al. 2005; Gopalakrishnan et al. 2013b). Using an iterative minimization procedure via a variable-storage Quasi-Newton M1QN3 algorithm (Gilbert and Lemaréchal 1989), the cost function descent reaches a plateau after 14 iterations with a relatively small slope (less than $1 \%$ per iteration) and the sum of the model-observation squared misfits normalized by the number of observations and the assumed observation variance were less than 1 for all data types. The total cost function is reduced by $46 \%$ after 14 iterations, and the individual observation costs decreased at roughly the same rate as the combined cost function. 
The optimized state estimate at the end of the assimilation period is used as initial conditions to forecast the ocean state for two months (April 30 - June 28, 2010), using monthly climatological open boundary conditions, atmospheric forcing, and run-off fluxes. Since the forecasts for lateral and atmospheric boundary conditions are generally available only for a period of about 3 days in a real time operational ocean hindcasting/forecasting system, we used monthly climatological forcings for the two-month long forecasts, so the forecast setup does not take advantage of possible predictability in the ocean and atmospheric boundary conditions as would be the case in an optimized system.

\section{MITgem-IAS EnKF Framework}

\section{a. MITgcm - Data Assimilation Research Testbed (MITgcm-DART)}

DART is an open-source software facility that provides a variety of algorithms for ensemble DA using both stochastic (e.g. ensemble Kalman filter - EnKF, (Evensen 2006)) and deterministic (e.g. ensemble adjustment Kalman filter - EAKF, (Anderson 2001, 2003)) Kalman filters. DART is also equipped with advanced inflation and localization schemes, very useful for good behavior of an EnKF (Anderson et al. 2009). Whereas localization tries to eliminate spurious correlations due to sampling errors, inflation mitigates for insufficient variance due to the omission of some sources of errors in the filter and in the model (Hoteit et al. 2002). The readers are referred to http://www .image .ucar .edu/DAReS/DART/ for further information about DART.

MITgcm was integrated to DART by Hoteit et al. (2013) and is recently applied in the Red Sea by Toye et al. (2017). MITgcm and DART run as separate executables with no modifications to each code. The exchanges of information between the two codes is handled through a set of interface routines. The state vector is exchanged by the two codes via the interface routines and 
is composed of the model prognostic variables, which in the case of the MITgcm are the salinity, temperature, horizontal velocities ( $U$ and $V$ ), and the two-dimensional SSH. The assimilation system is initialized from an ensemble of state vectors that is meant to represent the uncertainties around the initial state estimate. The MITgcm is then used as a forecast model to integrate the ensemble of state vectors forward in time. The resulting forecast ensemble is then sent to DART for updating with the incoming observations. The forecast-update cycles are then repeated every time new observations become available. A detailed description of the MITgcm-DART interface identical to that used in this study, with its application to the GoM can be found in Hoteit et al. (2013).

\section{b. MITgcm-IAS EnKF State Estimation Experiment}

The pre-processed along-track absolute SSH and gridded SST data, sampled over an assimilation window of 3 days, were assimilated sequentially using MITgcm-DART system for a period of 60 days (20 3-day assimilation cycles) starting from March 1, 2010 till April 29, 2010.

The filter parameters, including ensemble size, covariance inflation factor, localization length scale, and filter initialization are described in detail in Hoteit et al. (2013). We used EAKF and the filter initialization is based on an EOF analysis, as described in the background uncertainty section. The details of atmospheric forcings, open boundary conditions, and run-off fluxes of the MITgcm-IAS model are provided in Table 2. The MITgcm-DART results from the 2010 experiment discussed in the next section used 50 ensemble members, a spatially invariant inflation factor of 1.2, and localization radius of $250 \mathrm{~km}$ (EnKF2010-N50-I1.2-L250 in Table 4).

At the end of the 20 3-day assimilation cycles, an ensemble forecast was initialized using each ensemble member, in addition to a single forecast initialized from the ensemble mean analysis 
from the last assimilation cycle, for a period of two months (April 30 - June 28, 2010), using monthly climatological open boundary conditions, atmospheric forcing, and run-off fluxes.

\section{Comparison of Model Hindcast and Forecast with Observations}

The performance of MITgcm-ECCO and MITgcm-DART systems were analyzed by comparing the solutions with daily-interpolated gridded SSH fields from AVISO analysis (http: //marine.copernicus.eu/) and daily gridded SST data from TMI/AMSR-E for hindcasts and forecasts, and with Spray glider temperature and salinity observations for forecasts. The Ssalto/Duacs altimeter product AVISO is produced and distributed by the Copernicus Marine and Environment Monitoring Service (CMEMS) (http://marine. copernicus . eu/).

\section{a. Hindcast Comparison}

The SSH fields from MITgcm-ECCO (both the optimized solution from iteration 14: MIT4DVAR, and control "first-guess" solution: MIT-C) and MITgcm-DART (ensemble mean analysis: MIT-EnKF-A and forecast: MIT-EnKF-F) were compared with AVISO analysis and HYCOM/NCODA global daily analysis (HYCOM-GLOBAL). The model-data SSH comparisons at the start (March 1, 2010: Figure 2) and end (April 29, 2010: Figure 3) dates of the two-month hindcast period are shown for daily-averaged fields over the GoM basin (spatial domain highlighted by the blue curve in Figure 1). At the start, the MIT-4DVAR estimates of the LC shape and its westward and northward intrusion into the GoM basin are very similar to AVISO and HYCOMGLOBAL analysis. The model control adjustments that produced MIT-4DVAR by the iterative minimization process make only minor SSH changes compared to MIT-C. This means that the "first-guess" (MIT-C) forecast initialized with HYCOM/NCODA global daily analysis and using NCEP/NCAR-R1 forcing and HYCOM/NCODA boundary conditions provides realistic GoM cir- 
culation features, suggesting that HYCOM/NCODA analysis is remarkably compatible with the MITgcm-ECCO 4DVAR system.

The cyclonic Loop Current Frontal Eddies (LCFEs: (Vukovich and Maul 1985; Cochrane 1972; Vukovich et al. 1979; Fratantoni et al. 1998)) on the eastern side at the neck of the LC (centered roughly at $24^{\circ} \mathrm{N}, 276^{\circ} \mathrm{E}$ ), and near the northwestern side of the LC (centered roughly at $26^{\circ} \mathrm{N}, 272^{\circ} \mathrm{E}$ ) shown by MIT-4DVAR and MIT-C are also very similar to AVISO and HYCOMGLOBAL analysis. The presence of these LCFEs plays a determinant role in the LC eddy shedding (Schmitz 2005, 2003). The MIT-4DVAR and MIT-C reproduce the cyclonic eddies and the previously shed, slowly dissipating LC eddy in the southwestern GoM basin seen in the AVISO and HYCOM-GLOBAL analysis. The MIT-EnKF-F starting SSH is the long-term mean of a five-year (2004 - 2008) forward model simulation (Gopalakrishnan et al. 2013a), based on which the ensemble members were generated, and therefore differs from the AVISO and HYCOM-GLOBAL analysis. In order to clearly demonstrate the performance of the MITgcm-DART, and to be consistent with the ensemble covariance which is relative to the mean background state, the filter is initialized using EOFs of a large set of MITgcm-IAS forward model realizations which are referenced to its long-term mean rather than HYCOM/NCODA $1 / 12^{\circ}$ global daily analysis used in the MITgcm-ECCO initialization. In spite of these starting differences, MIT-EnKF-A (after the first assimilation cycle) shows many of the AVISO analysis SSH features, especially the location of an older, dissipating LC eddy and the cyclonic eddies in the southwestern GoM basin, and a LCFE on the northwestern side of the $\mathrm{LC}$ (centered roughly at $26^{\circ} \mathrm{N}, 272^{\circ} \mathrm{E}$ ). It however fails to reproduce the LCFE on the eastern side near the neck of the LC, likely due to the limited observations in the 3 day window. It is remarkable that the MIT-EnKF-A is able to reproduce most of the AVISO analysis SSH features after only one assimilation cycle. 
At the end date of the hindcast period, the SSH fields from MIT-4DVAR, MIT-EnKF-A, and MIT-EnKF-F show similar LC northward and westward extent to the AVISO and HYCOMGLOBAL analysis, but MIT-C differs. Also all estimates except MIT-C reasonably reproduce the size, shape, and location of the older, dissipating LC eddy and cyclonic eddy features in the southwestern GoM basin. It should be noted that there are only small differences between MITEnKF-A and MIT-EnKF-F at the end of the hindcast period.

The model SST fields were compared with TMI/AMSR-E data and HYCOM-GLOBAL analysis at the end of the hindcast period (Figure 4). Except for MIT-C, SST estimates compare well with TMI/AMSR-E data and HYCOM-GLOBAL analysis, especially the LC shape and temperature, and the cooling of the northern GoM basin. Model SST shows a warmer southwestern GoM basin with a positive bias of $\sim 2^{\circ} \mathrm{C}$ compared to TMI/AMSR-E data and HYCOM-GLOBAL analysis. Again, the SST of MIT-EnKF-A and MIT-EnKF-F are very similar at the end of the hindcast period.

For more quantitative comparisons, the daily-averaged SSH from the MITgcm-ECCO and MITgcm-DART hindcasts as well as HYCOM/NCODA global daily analysis are compared to the AVISO analysis SSH. For MITgcm-ECCO, the hindcast rmsd curves from MIT-4DVAR, MIT-C, model-persistence (MIT-P), and HYCOM-GLOBAL are shown in Figure 5a. The MIT-P solution is assumed to be constant over the whole hindcast period and is equal to the MIT-4DVAR initial state. The MIT-4DVAR hindcast has an overall rmsd of $6 \mathrm{~cm}$, lower than the HYCOM-GLOBAL analysis throughout the hindcast period, and shows considerable reduction in the rmsd (about 50 $\%$ near the end of the assimilation period) when compared with MIT-P and MIT-C.

The AVISO gridded SSH are estimated by Optimal Interpolation, merging the measurements from the different altimeter missions available, and is the Absolute Dynamic Topography (ADT) which is equal to Sea Level Anomaly (SLA) + time-Mean Dynamic Topography (MDT) with 
respect to a twenty-year $(1992$ - 2012) mean. While the mapped AVISO product is not necessarily the true SSH state, it is a widely-used benchmark and has small differences with the satellite alongtrack SSH observations. Computing SSH rmsd with the assimilated along-track observations from RADS (not shown) gives misfit time-series that are qualitatively similar, but are much less smooth, as well as less homogeneous due to fluctuating numbers of observations from day to day depending on when altimeters sample the domain. The space-time smoothness of the AVISO analysis makes it more convenient as a reference for SSH $r m s d$ comparison given that the true SSH is not available.

The SSH hindcast rmsd comparison for the MITgcm-DART experiment is shown in Figure 5b. The MIT-EnKF solutions over the 20 3-day assimilation cycles were linearly interpolated between the analyses for the rmsd computation. As before, the MIT-P estimate held the MIT-EnKF-A initial state constant over the hindcast period. As expected, the MIT-EnKF-A has the lowest $r m s d$, showing the most rmsd reduction compared to MIT-EnKF-F during the first three analysis cycles. Overall, MIT-EnKF-A shows a rmsd of $6 \mathrm{~cm}$, lower than HYCOM-GLOBAL throughout the hindcast period. The ensemble standard deviation (spread) (thick dashed lines), and total error (ensemble spread + observation error of $5 \mathrm{~cm}$, thin dashed lines) averaged over the GoM basin for both analysis (red curves) and forecasts (black curves) are also shown in Figure 5b. The ensemble spread starts at $7.5 \mathrm{~cm}$ for forecast and $6 \mathrm{~cm}$ for analysis, drops to about $2.5 \mathrm{~cm}$ after the third analysis cycle for both analysis and forecast, and stays close to this value throughout the hindcast period. The total spread curves for analysis and forecast show that MITgcm-DART fits SSH within the prior estimates of observation error throughout the two-month hindcast period, although it is possible that the spread is too small and the assumed observation error is too large.

In general, both MIT-4DVAR and MIT-EnKF-A solutions show similar $r m s d$ during the hindcast period, closely following the HYCOM-GLOBAL analysis and outperforming MIT-P. 


\section{b. Forecast Comparison}

The SSH fields as forecasted by MIT-4DVAR, MIT-C, MIT-EnKF-Ens, and MIT-EnKF-Ave are visually compared to AVISO and HYCOM-GLOBAL analysis at the end of the first month (May $29,2010)$ of the two-month forecast period in Figure 6. MIT-EnKF-Ens refers to the forecast initialized from the EnKF ensemble mean analysis (MIT-EnKF-A) at the end of the hindcast, MIT-EnKF-Ave is the mean of forecasted ensemble states, MIT-4DVAR was initialized from the end of the MITgcm-ECCO optimized state, and MIT-C was initialized using the optimized state from $\mathrm{HYCOM} / \mathrm{NCODA} 1 / 12^{\circ}$ global daily analysis for the start date of the forecast.

MIT-C exhibits a well connected LC, without any formation and detachment of a LC eddy. MIT4DVAR forecasts a LC eddy (Eddy-F) close to detachment from the LC, and the structure of the LC and the size, shape, and location of the newly-formed eddy compares well with AVISO and HYCOM-GLOBAL analysis. In addition, the MIT-4DVAR forecast shows a small cyclonic LCFE on the eastern side of the LC, between the LC and the newly formed Eddy-F (centered roughly at $24^{\circ} \mathrm{N}, 276^{\circ} \mathrm{E}$ ), in agreement with AVISO and HYCOM-GLOBAL analysis. The presence of these cyclonic LCFEs might trigger the LC eddy shedding processes in the GoM (Schmitz 2005, 2003; Le Hénaff et al. 2012; Vukovich and Maul 1985; Cochrane 1972; Vukovich et al. 1979; Fratantoni et al. 1998). Both MIT-4DVAR and MIT-C correctly predict the older, dissipating LC eddy in the western GoM basin, as seen in AVISO and HYCOM-GLOBAL analysis. MIT-EnKF-Ens and MIT-EnKF-Ave predict very similar features of the LC and the newly formed eddy (Eddy-F), and the small-scale cyclonic LCFE on the east side of the LC (centered roughly at $24^{\circ} \mathrm{N}, 276^{\circ} \mathrm{E}$ ) with the Eddy-F just detached, whereas MIT-4DVAR forecast and AVISO analysis suggest Eddy-F is close to detachment from the LC, as previously mentioned. The coarse horizontal resolution (10 $\mathrm{km})$ and high viscosity and diffusivity coefficients of the MITgcm-IAS forecast model might cause 
the smoother and more circular LC eddy (Eddy-F) relative to AVISO and HYGOM-GLOBAL analysis.

MIT-4DVAR, MIT-C, MIT-EnKF-Ens, and MIT-EnKF-Ave forecasts of the three-dimensional temperature and salinity were also compared with the Spray glider data in the GoM during June 2010 (Section 3). The model forecasts were linearly interpolated in time and space to the glider observations. The glider observations and differences with MIT-4DVAR (obs - MIT-4DVAR), MIT-C (obs - MIT-C), MIT-EnKF-Ens (obs - MIT-EnKF-Ens), and MIT-EnKF-Ave (obs - MITEnKF-Ave) are shown in Figure 7. The anomaly root-mean-square-difference: $r m s d_{a}$ and anomaly correlation coefficient: $c c_{a}$ (Gopalakrishnan et al. 2013b) between observed and model forecast subsurface temperature and salinity profiles were computed and labeled in Figure 7. A decrease (increase) in $\operatorname{rmsd}_{a}\left(c c_{a}\right)$ indicates an improved model forecast. MIT-4DVAR, MIT-EnKF-Ens, and MIT-EnKF-Ave compare better with the glider data than MIT-C, with the MIT-EnKF-Ave providing the closest solution to the glider data. MIT-4DVAR exhibits a lower (higher) $r m s d_{a}$ for temperature (salinity) compared to MIT-EnKF-Ens. The results of the comparison differ for temperature and salinity and above and below $50 \mathrm{~m}$ depth. MIT-4DVAR, MIT-EnKF-Ens, and MIT-EnKF-Ave temperature forecasts show significant improvement at depth because the altimeter data can accurately constrain isopycnal displacements, while not improving the surface likely due to the large SST observation errors assumed and the dominance of atmospheric forcing over ocean dynamics in determining SST. The salinity shows similar improvements at depth, although the amplitude of the signal is smaller, reflecting the weaker vertical gradients of salinity. Irrespective of these two distinct approaches, both assimilation systems produced improved forecasts compared to MIT-C for SSH, as well as for subsurface temperature and salinity fields. 
c. Ensemble Forecasts

Ensemble forecasting can boost forecast skill and provide an efficient model-based estimate of uncertainties. The daily-averaged SSH fields from MITgcm-DART ensemble member forecasts, along with MIT-4DVAR, MIT-C, MIT-EnKF-Ens, MIT-EnKF-Ave, and HYCOM-GLOBAL analysis, are differenced from the AVISO analysis SSH for the two month forecast period (May - June, 2010). The corresponding model-data $r m s d$ is shown in Figure 8a. Please note that the y-axis of this figure spans $5 \mathrm{~cm}$ to $20 \mathrm{~cm}$ to show the details. The MIT-4DVAR persistence (MIT-4DVARP) forecast assumed the MIT-4DVAR forecast initial state fixed over the forecast period, while the MIT-EnKF-Ens persistence (MIT-EnKF-Ens-P) forecast assumed the MIT-EnKF-Ens forecast initial state fixed over the forecast period.

The MIT-4DVAR forecast has an overall $r m s d$ of $9 \mathrm{~cm}$, while the MIT-4DVAR-P rmsd increases from $7 \mathrm{~cm}$ to $18 \mathrm{~cm}$ over the forecast period. The MIT-C rmsd is comparable to MIT-4DVAR and HYCOM-GLOBAL during the first week of the forecast, but shows a slightly increased rmsd compared to MIT-4DVAR after the third week. The MIT-EnKF-Ens and MIT-EnKF-Ave forecasts remain closer to HYCOM-GLOBAL with an overall $r m s d$ of $7 \mathrm{~cm}$ during the first two weeks, after which MIT-EnKF-Ens performance degrades, reaching a rmsd of $15 \mathrm{~cm}$ by the end of the forecast period. MIT-C forecast on the other hand shows an overall $\mathrm{rms} d$ of $10 \mathrm{~cm}$ over the forecast period, which is lower than MIT-EnKF-Ens forecast starting from the fifth week, but higher than MITEnKF-Ave throughout the forecast period.

The range of SSH rmsd of the ensemble forecast members increases with time and shows a larger rmsd ranging from $8 \mathrm{~cm}$ to $17 \mathrm{~cm}$ at the end of the forecast period, after starting from a smaller $r m s d$ ranging from $7 \mathrm{~cm}$ to $8 \mathrm{~cm}$. The starting SSH forecast $r m s d$ from ensemble members shows a single outlier with higher $(>8.5 \mathrm{~cm}) \mathrm{rmsd}$, which is not a healthy behavior in an EnKF. 
Sakov and Oke (2008) suggested that the use of mean-preserving random rotations in an ensemble square root filter could help mitigate the buildup of ensemble outliers. The rmsd of this outlier member did not however grow large enough over the 60-day forecast period to require introducing a random rotation to the mean-preserving EAKF used here. Out of all forecasts, MIT-EnKFAve shows comparable rmsd to that of HYCOM-GLOBAL, except during the last three weeks of the forecast period. MIT-4DVAR-P and MIT-EnKF-Ens-P have the highest rmsd throughout the forecast period.

MIT-EnKF-Ens provides a better forecast than MIT-C during the first five weeks of the forecast period, whereas MIT-4DVAR shows a better forecast than MIT-C from the third week onward. The MIT-EnKF-Ave forecast provides the best performance out of all solutions. As expected, the mean of ensemble forecasts (MIT-EnKF-Ave) performs better than a single forecast from the ensemble mean analysis (MIT-EnKF-Ens). Depending on the available computational resources, an ensemble forecast might not be practical, especially with many ensemble members in highresolution ocean prediction systems. In that case, one might want to rely on a single forecast starting from the ensemble mean analysis. Comparing the two assimilation systems, the MIT4DVAR performs better over long-range (about eight-weeks) SSH forecasts, and MIT-EnKF-Ens performs better over short-range (up to about four-weeks) SSH forecasts, while both systems show similar performance during the hindcast period.

In addition to the comparison of the model forecasts with AVISO analysis, a set of LC indices (Leben 2005) were also computed by tracking a calibrated $17 \mathrm{~cm} \mathrm{SSH}$ isoline in the various model solutions and AVISO. The AVISO analysis SSH were interpolated to the model grid to provide the reference for this comparison. Following the procedure reported by Leben (2005), the LC indices, specifically the maximum western longitude, maximum northern latitude, and length of the LC were computed from daily-averaged SSH fields during the forecast period, including ensem- 
ble forecasts, although only the northward extent index is shown in Figure 8b. The MIT-4DVAR shows an LC eddy (Eddy-F) detachment at the same day (May 30, 2010) as the AVISO analysis, but does not show the LC eddy reattachment seen by AVISO analysis in late June 2010. Both MIT-EnKF-Ens and MIT-EnKF-Ave predict a LC eddy detachment around the last week of May, 2010, close to MIT-4DVAR and AVISO analysis, but the MIT-EnKF-Ens suggests an immediate reattachment of the LC eddy within two weeks, while MIT-EnKF-Ave shows a LC eddy reattachment at almost the same time as AVISO analysis. Even though all model forecasts used the same monthly climatological atmospheric forcings, open boundary conditions, and run-off fluxes, MIT4DVAR seems to preserve the large-scale features of the LC but fails to reproduce the LC eddy reattachment shown by MIT-EnKF-Ave and AVISO analysis, suggesting that the initial conditions are important.

To further examine the evolution of the LC and eddy detachment/reattachment, the $17 \mathrm{~cm} \mathrm{SSH}$ isoline from model forecasts, ensemble forecasts, and AVISO analysis are plotted for days 1, 14, 21, and 28 of the two-month forecast period (Figure 9). For the MIT-EnKF-Ave, the $17 \mathrm{~cm} \mathrm{SSH}$ contour is computed from the mean of SSH forecasts from each ensemble member. On day 1, the LC shape from MIT-EnKF-Ens solutions stays closer to AVISO analysis than MIT-4DVAR, and the ensemble forecasts show very little spread (see Figure 10), reflecting the EnKF's expectation that it has a good nowcast of the field. As the time progresses to day 14, all model solutions estimate similar LC shape on the western side of LC, while exhibiting some differences on the eastern side, especially near the neck of the LC. On day 21 , the LC features are more or less similar to that of day 14 , with more pronounced formation of the LC eddy and differences on the eastern side near the neck of the LC, and larger ensemble spread (see Figure 10) in this region. On day 28, the MIT-EnKF-Ens and MIT-EnKF-Ave show an already detached LC eddy with a larger 
ensemble spread near the region of LC eddy detachment, while both MIT-4DVAR and AVISO analysis suggest a LC eddy close to detachment from the LC.

The ensemble mean and spread of the MITgcm-DART SSH forecast are shown in Figure 10,

for the same days as Figure 9. The ensemble spread starts with structures showing satellite tracks and increases as forecast time progresses, predominantly along the LC, showing higher values near the neck of the LC where the LC eddy detachment is thought to start, as shown in Figure 9. The SSH ensemble spread also increases near the cyclonic LCFE's on the eastern side of the LC, between the newly formed LC eddy and the LC, and also in the western GoM, where the previously shed LC eddy dissipates near the western boundary. The SSH ensemble mean shows a LC eddy just detached from the LC at the end of the first month of the two-month forecast as well as cyclonic small-scale LCFE's on the eastern side of the LC. The SSH ensemble mean and spread give information about the key regions that affect the LC forecasts in the GoM, especially during a LC eddy shedding event, and provide insight into the processes that drive the LC circulation and eddy shedding.

\section{d. Sensitivity to Filter Parameters}

A series of experiments were performed with the MITgcm-DART system using the same observations and forecast model but varying the ensemble size, covariance inflation parameter, localization length scale, and finally the number of assimilation cycles (hindcast period). The details of these experiments are listed in Table 4. As before, the SSH estimates from these experiments were compared to AVISO analysis during the hindcast and forecast periods, and the corresponding model-data $r m s d$ were analyzed, focusing on the model performance during the two-month forecast period. In every experiment MIT-EnKF-Ave always led to a lower rmsd compared to a single forecast starting from the ensemble mean analysis (MIT-EnKF-Ens) at the end of the hindcast 
period. Increasing the number of ensemble members from 25 , to 50 , and to 100 , while using the same inflation factor of 1.2 and localization radius of $500 \mathrm{~km}$, the MIT-EnKF-Ens forecast rmsd decreases from $18 \mathrm{~cm}$ for 25 members to $12 \mathrm{~cm}$ for 100 members (Figure 11a). Please note that the y-axis of all panels in Figure 11 spans $6 \mathrm{~cm}$ to $16 \mathrm{~cm}$ to show the details. Larger ensembles provide more degrees of freedom and spread, which allows a closer fit to observations and seem to result in better analysis state in these cases. Increasing the inflation factor from 1.2 to 1.3 while keeping the same ensemble size 50 and localization radius of $500 \mathrm{~km}$ is clearly worse with the MIT-EnKF-Ens forecast showing slightly increased rmsd for the experiment with inflation factor of 1.3, while both experiments show almost the same MIT-EnKF-Ens forecast rmsd at the end of the forecast period (Figure 11b). Two experiments were performed decreasing the localization radius from $500 \mathrm{~km}$ to $250 \mathrm{~km}$, while keeping the same ensemble size and inflation of 1.2 for 25 and 50 members. Both experiments resulted in markedly improved forecast $r m s d$ during the first few weeks, with the 25 member experiments showing more improvement throughout the forecast period (Figure 11c). This is expected since the smaller ensemble has less freedom to fit the observations and should benefit the most from localization. Although decreasing the localization length scale enables a better fit to the observations, it may degrade the dynamical balance of the estimates. Finally, we decreased the number of assimilation cycles (the length of the hindcast period) from two months to one month and then to two weeks, while keeping the same ensemble size of 25 members, inflation factor of 1.2, and localization radius of $250 \mathrm{~km}$. The short-term forecast (one to two weeks) from the two week hindcast period improves, but the overall forecast performance degrades with the decreasing length of the assimilation (Figure 11d). With longer hindcast periods, the ensemble spread decreases with the number of assimilation cycles, and often results in unrealistically small spreads toward the end of the hindcast period, which limits the fit to the observations. Conversely, a shorter hindcast period maintains a better ensemble spread to the 
end of the hindcast period, allowing a better fit to the observations and more spread to initialize the ensemble forecasts. although the final state may be worse because fewer data were used.

\section{e. Other Assimilation Experiments}

The MITgcm-DART and MITgcm-ECCO were applied to three other periods to compute state estimates and forecasts of the GoM circulation. The details of the three additional experiments are as follows: 1) 2006: hindcast (July - August, 2006), forecast (September - October, 2006), 2) 2013: hindcast (January - February, 2013), forecast (March - April, 2013), and 3) 2014: hindcast (February, 2014), forecast (March - April, 2014) are provided in Table 4 (MITgcm-DART experiments) and Table 5 (MITgcm-ECCO experiments). Both MITgcm-DART and MITgcm-ECCO followed the same settings as those of the 2010 experiment, but there were some changes in the observations assimilated. The 2006 and 2010 experiments used SSH along-track data from satellites J1, J2, and N1, and TMI/AMSR-E gridded SST data, whereas the 2013 and 2014 experiments used SSH along-track data from J2, Saral Altika (Sa), and CryoSat-2 (C2) satellites. The results were analyzed following a similar procedure to that used in the 2010 experiment. In particular, we examined the model-data SSH rmsd with the AVISO analysis, focusing on the forecast performance.

The 2006 experiment focused on the LC eddy Yankee (Eddy-Y), which showed initial detachment in July 2006 and reattached and detached multiple times before it finally permanently separated in January 2008 as per http://www.horizonmarine.com/loop-current-eddies .html. The MITgcm-ECCO experiments were performed for July 1 - August 29, 2006, and MITgcmDART experiments were performed for the same period (60 days, with 20 assimilation cycles of 3-day assimilation window), using two ensemble sizes: 25 and 100, both with an inflation factor of 1.2 and localization radius of $250 \mathrm{~km}$. The MIT-4DVAR forecast shows better performance 
compared to MIT-EnKF-Ens forecasts using 25 and 100 ensemble members, even with the shorter localization radius, and MIT-C forecast initialized using HYCOM/NCODA $1 / 12^{\circ}$ global daily analysis (Figure 12a). Please note that the y-axis of all panels in Figure 12 spans $5 \mathrm{~cm}$ to 20 $\mathrm{cm}$ to show the details. The MIT-EnKF-Ens forecast performance improves when the ensemble size is increased from 25 to 100. The hindcast period (July - August, 2006) exhibited a more dynamically-active LC circulation, with Eddy-Y detaching/reattaching to the LC (not shown), and the LC circulation is more complicated than in the 2010 experiment, where the LC was in the slowly-evolving growth/extension phase. This may be why even 100 ensemble members were not sufficient to match MIT-4DVAR forecast.

The 2013 and 2014 experiments focused on the formation of LC eddy Kraken (Eddy-K), which first detached in April 2013 and finally permanently separated in October 2014 after multiple detachment/reattachment with the LC as per http://www.horizonmarine.com/ loop-current-eddies.html. The assimilation experiments were performed during January 1 - March 1, and February 1 - 27, for 2013 and 2014, respectively. For 2013 and 2014, MITgcmDART was implemented with 25 ensemble members, inflation factor of 1.2, localization radius of $250 \mathrm{~km}$, and a hindcast period of 60 days (20 assimilation cycles of 3-day assimilation window) for 2013 and 27 days (9 assimilation cycles of 3-day assimilation window) for 2014. In 2013, the MIT-C forecast is best beyond one month. The MIT-4DVAR forecast starts off with a large $r m s d$ compared to MIT-C and MIT-EnKF-Ens forecasts, but has slower rmsd growth toward the end of the forecast period compared to MIT-EnKF-Ens. The MIT-EnKF-Ens provides comparable rmsd to MIT-C during the first week of the forecast period and then diverges from MIT-C, showing larger rmsd toward the end of the forecast period (Figure 12b). In 2014, MIT-C and MIT-EnKFEns closely match during the early stage, but MIT-4DVAR provides a better solution at the end of the forecast period (Figure 12c). Again, for all MITgcm-DART experiments the mean of the 
ensemble forecasts (MIT-EnKF-Ave) showed lower rmsd compared to a single forecast starting from the ensemble mean analysis (MIT-EnKF-Ens).

Overall, both systems lead to mixed forecast performances, with generally better long-term forecasts by MITgcm-ECCO and more accurate short-term forecasts by MITgcm-DART. The forecast skill from both methods greatly depends on the background state of the LC and eddy circulation in the GoM. During slowly-evolving LC growth/extension phase, the LC system appears to be more linear and both methods produce reasonable, comparable forecasts, even with fewer ensemble members for MITgcm-DART. Whereas forecast skill from both methods degrades during dynamically-active LC eddy detachment/reattachment and permanent separation phases.

\section{Summary and Conclusions}

A comprehensive comparison of 4DVAR and EnKF ocean DA systems was conducted using a realistic application of the MITgcm to analyze and predict the LC circulation in the GoM. The ocean state estimates and forecasts from MITgcm-ECCO 4DVAR and MITgcm-DART EnKF systems and the contribution of ensemble prediction were evaluated by comparing with AVISO SSH analysis and TMI/AMSR-E gridded SST data for hindcasts and forecasts, and with Spray glider subsurface temperature and salinity observations for forecasts. The mean predicted state from ensemble forecasts was always seen to be superior to the predicted state from the ensemble mean analysis. The SSH and SST hindcasts from both systems were comparable and they follow closely the HYCOM/NCODA global daily analysis. The SSH forecasts from both systems, including ensemble forecasts, significantly outperformed their respective persistence forecasts (Figure 8a). The reference forecast initialized from assimilated HYCOM/NCODA daily global solutions were often as good as the forecasts from both systems, suggesting that HYCOM/NCODA provides another competitive model initialization. Additionally, while the MITgcm-ECCO 4DVAR results 
presented in this work and in Gopalakrishnan et al. (2013b) are not exactly the same, they do appear very similar. This suggests that the inclusion of atmospheric forcing and open boundary controls had a small effect in this two-month short-term state estimate, at least with respect to this model, 4DVAR assimilation set up, parameters, background uncertainty covariances for model and observations, and times, which is an interesting result. Earlier, using Ensemble Optimal Interpolation (EnOI), Counillon and Bertino (2009) reported that changes in the lateral and surface boundary conditions appeared to control the propagation of LCFEs along the edge of the LC and contribute to the ensemble spread in the GoM.

The MITgcm-ECCO controls allow independent adjustment of the model initial conditions for temperature and salinity, while the MITgcm-DART builds in correlations between the fields. MITgcm-DART better deals with non-linearities and can propagate uncertainties forward. It however only provides limited degrees of freedom to fit the data depending on the ensemble size. Localization and inflation are then needed to obtain good performance. The MITgcm-DART estimates are generally closer to the observations, but typically require several assimilation cycles before reaching an acceptable solution, whereas MITgcm-ECCO estimates are dynamicallyconsistent over the whole hindcast period.

The MITgcm-DART experiments varying the ensemble size, covariance inflation, localization length scale, and number of assimilation cycles outlined the sensitivity of the ensemble forecasts to filter parameters. In general, MITgcm-DART predictions were enhanced by increasing the ensemble size. A larger ensemble provides more degrees of freedom and spread, which usually lead to a better analysis state. The MITgcm-DART predictability also improved with decreased localization length scale. A finer localization length scale enables a better fit with the observations, but may degrade the dynamical balance of the solutions (Houtekamer and Mitchell 2005). MITgcmDART also showed better short-term predictability when using shorter hindcast periods (fewer 
assimilation cycles) down to two weeks. This result is specific to the MITgcm-DART system and filter parameters used in this study, and cannot be generalized, but in this case, a shorter hindcast period might maintain a better ensemble spread toward the end of the hindcast period, leading to a better fit with observations, and more spread to initialize the ensemble forecasts. On the other hand, a properly tuned EnKF system is equally capable of maintaining ensemble spread over a longer hindcast period, and can efficiently fit the observations to provide good initializations for ensemble forecasting.

The MITgcm-DART ensemble forecasts provide enhanced predictions from the ensemble mean and an uncertainty estimate from the spread. The ensemble SSH spread increased with forecast time, as expected, and is largest in the regions of high SSH gradients such as the LC, the region of cyclonic LCFEs, and in the regions of LC eddy dissipation in the western GoM basin. The ensemble mean and spread highlight regions that affect the LC predictability and the spatial-temporal processes that might trigger LC eddy separation in the GoM.

The present work demonstrates a practical application of both assimilation methods for the GoM and performs a reasonable comparison between them. The overall conclusion is that, for the LC circulation in the GoM in these realizations, MITgcm-DART provided better short-term predictability (less than four weeks), while MITgcm-ECCO provided better long-term predictability (longer than four weeks). The conclusion from this study are however specific to a few 4DVAR and EnKF LC eddy separation experiments in the GoM and cannot be generalized to conclude the relative performances of both methods. The predictability results suggest the hypothesis that while the 4DVAR fit over a long time period and could not get as close to the observations as the sequential method, it is not limited to a reduced state space like ensemble methods and so can get closer to the true state which should lead to better long-term predictability. The MITgcm-ECCO and MITgcmDART experiments in the GoM suggest that the performance of both systems critically depends 
on the background state of the circulation in the GoM, which ranges from the slowly-evolving LC growth/extension phase, to the dynamically-active LC eddy detachment/reattachment and permanent separation phase. For this reason, among others, this study is only a start at understanding the trade-offs between methods because of the many cases that could be tried and the large parameter space to explore, including model resolution and mixing parameterizations.

Acknowledgments. We gratefully acknowledge the ECCO consortium, including MIT, JPL, and the University of Hamburg and the NCAR Data Assimilation Research Section (DAReS). The MITgcm code used in this study is checkpoint 64Y, and were obtained from http://mitgcm . org/. The Ssalto/Duacs altimeter product AVISO is produced and distributed by the Copernicus Marine and Environment Monitoring Service (CMEMS) (http://marine.copernicus.eu/). The HYCOM/NCODA $1 / 12^{\circ}$ global analysis were obtained from the HYCOM consortium (http: //hycom.org/dataserver/). The along-track altimetry data were obtained from the Radar Altimetry Database System (RADS), (http://rads.tudelft.nl/rads/index.shtml). The SST data were obtained from the Remote Sensing Systems Inc. (http://www.remss.com/). The NCEP/NCAR-Reanalysis-1 atmospheric forcings were obtained from the http://www.esrl. noaa.gov/psd/data/gridded/data.ncep.reanalysis.html. The MITgcm-DART EnKF and MITgcm-ECCO 4DVAR state estimates, input files including observations and error fields, are available from the authors upon request (ggopalakrishnan@ucsd.edu). BDC is supported by the Office of Naval Research Award Number: XXXX. GG is supported by the National Academy of Sciences Award Number: XXXX

\section{References}

Aksoy, A., D. C. Dowell, and C. Snyder, 2009: A multicase comparative assessment of the Ensemble Kalman Filter for assimilation of radar observations. Part I: Storm-scale analyses. Mon. 
Wea. Rev., 137, 1805-1824.

Andersen, O., and P. Knudsen, 2009: DNSC08 Mean Sea Surface and Mean Dynamic Topography models. Journal of Geophysical Research, 114 (C11), C11 001.

Anderson, J., 2001: An ensemble adjustment Kalman filter for data assimilation. Monthly weather review, 129, 2884-2903.

Anderson, J., 2003: A local least squares framework for Ensemble Filtering. Monthly Weather Review, 131, 634-642.

Anderson, J., T. Hoar, K. Raeder, H. Liu, N. Collins, R. Torn, and A. Avellano, 2009: The Data Assimilation Research Testbed: A Community Facility. Bulletin of the American Meteorological Society, 90 (9), 1283-1296.

Bertino, L., K. Lisæter, and S. Scient, 2008: The TOPAZ monitoring and prediction system for the Atlantic and Arctic Oceans. Journal of Operational Oceanography, 1 (2), 15-18.

Brasseur, P., P. Bahurel, L. Bertino, F. Birol, J.-M. Brankart, N. Ferry, S. Losa, E. Rémy, J. Schröter, S. Skachko, and Coauthors, 2005: Data assimilation for marine monitoring and prediction: The MERCATOR operational assimilation systems and the MERSEA developments. Quarterly Journal of the Royal Meteorological Society, 131 (613), 3561-3582.

Buehner, M., P. Houtekamer, C. Charette, H. L. Mitchell, and B. He, 2010: Intercomparison of variational data assimilation and the Ensemble Kalman Filter for global deterministic NWP. Part II: One-month experiments with real observations. Monthly Weather Review, 138 (5), 15671586. 
Chassignet, E., H. Hurlburt, O. Smedstad, G. Halliwell, P. Hogan, A. Wallcraft, R. Baraille, and R. Bleck, 2007: The HYCOM (HYbrid Coordinate Ocean Model) data assimilative system. Journal of Marine Systems, 65 (1-4), 60-83.

Cochrane, J., 1972: Separation of an anticyclone and subsequent developments in the Loop Current (1969). Contributions on the Physical Oceanography of the Gulf of Mexico, 2, 91-106.

Counillon, F., and L. Bertino, 2009: High-resolution ensemble forecasting for the Gulf of Mexico eddies and fronts. Ocean Dynamics, 59 (1), 83-95.

Dowell, D. C., and L. Wicker, 2009: Additive noise for storm-scale ensemble data assimilation. $J$. Atmos. Ocean. Technol., 26, 911-927.

Edwards, C. A., A. M. Moore, I. Hoteit, and B. D. Cornuelle, 2015: Regional ocean data assimilation. Annual review of marine science, 7, 21-42.

Evensen, G., 2006: Data Assimilation: The Ensemble Kalman Filter. Springer.

Forget, G., 2009: Mapping ocean observations in a dynamical framework: a 2004-2006 ocean atlas. Journal of Physical Oceanography.

Forget, G., J.-M. Campin, P. Heimbach, C. Hill, R. Ponte, and C. Wunsch, 2015: ECCO version 4: an integrated framework for non-linear inverse modeling and global ocean state estimation. Geoscientific Model Development Discussions, 8, 3653-3743.

Fratantoni, P., T. Lee, G. Podesta, and F. Muller-Karger, 1998: The influence of Loop Current perturbations on the formation and evolution of Tortugas eddies in the southern Straits of Florida. Journal of Geophysical Research-Oceans, 103 (C11), 24759.

Gebbie, G., P. Heimbach, and C. Wunsch, 2006: Strategies for nested and eddy-permitting state estimation. Journal of Geophysical Research (Oceans), 111 (C10), 10073. 
Ghil, M., and P. Malanotte-Rizzoli, 1991: Data Assimilation in Meteorology and Oceanography. Advances in Geophysics, 33, 141-266.

Gilbert, J., and C. Lemaréchal, 1989: Some numerical experiments with variable-storage quasiNewton algorithms. Mathematical programming, 45 (1), 407-435.

Gopalakrishnan, G., B. D. Cornuelle, and I. Hoteit, 2013a: Adjoint sensitivity studies of loop current and eddy shedding in the Gulf of Mexico. Journal of Geophysical Research: Oceans, 118 (7), 3315-3335.

Gopalakrishnan, G., B. D. Cornuelle, I. Hoteit, D. L. Rudnick, and W. B. Owens, 2013b: State estimates and forecasts of the loop current in the Gulf of Mexico using the MITgcm and its adjoint. Journal of Geophysical Research: Oceans, 118 (7), 3292-3314.

Hoteit, I., B. Cornuelle, and P. Heimbach, 2010: An eddy-permitting, dynamically consistent adjoint-based assimilation system for the Tropical Pacific: Hindcast experiments in 2000. Journal of Geophysical Research, 115 (C3), C03 001.

Hoteit, I., B. Cornuelle, S. Kim, G. Forget, A. Köhl, and E. Terrill, 2009: Assessing 4D-VAR for dynamical mapping of coastal high-frequency radar in San Diego. Dynamics of Atmospheres and Oceans, 48 (1-3), 175-197.

Hoteit, I., B. Cornuelle, A. Köhl, and D. Stammer, 2005: Treating strong adjoint sensitivities in tropical eddy-permitting variational data assimilation. Quarterly Journal of the Royal Meteorological Society, 131 (613), 3659-3682.

Hoteit, I., T. Hoar, G. Gopalakrishnan, N. Collins, J. Anderson, B. Cornuelle, A. Köhl, and P. Heimbach, 2013: A MITgcm/DART ensemble analysis and prediction system with application to the Gulf of Mexico. Dynamics of Atmospheres and Oceans, 63, 1-23. 
Hoteit, I., D. Pham, and J. Blum, 2002: A simplified reduced order Kalman filtering and application to altimetric data assimilation in Tropical Pacific. Journal of Marine Systems, 36, 101-127.

Houtekamer, P., and H. Mitchell, 2005: Ensemble Kalman Filtering. Q. J. R. Meteorol. Soc., 131, $3269-3289$.

Kalnay, E., M. Kanamitsu, R. Kistler, W. Collins, D. Deaven, L. Gandin, M. Iredell, S. Saha, G. White, J. Woollen, and Coauthors, 1996: The NCEP/NCAR 40-year reanalysis project. Bulletin of the American meteorological Society, 77 (3), 437-472.

Keppenne, C., M. Rienecker, N. Kurkowski, and D. Adamec, 2005: Ensemble Kalman Filter assimilation of temperature and altimeter data with bias correction and application to seasonal prediction. Nonlin. Proc. Geophys., 12, 491-503.

Köhl, A., D. Stammer, and B. Cornuelle, 2007: Interannual to decadal changes in the ECCO global synthesis. Journal of Physical Oceanography, 37 (2), 313-337.

Korres, G., K. Nittis, L. Perivoliotis, K. Tsiaras, A. Papadopoulos, G. Triantafyllou, and I. Hoteit, 2010: Forecasting the Aegean Sea hydrodynamics within the POSEIDON-II operational system. Journal of Operational Oceanography, 38, 37-49.

Large, W., J. McWilliams, and S. Doney, 1994: Oceanic Vertical Mixing: A Review and a Model with a Nonlocal Boundary Layer Parameterization. Reviews of Geophysics, 32 (4), 363-403.

Large, W., and S. Pond, 1981: Open ocean momentum flux measurements in moderate to strong winds. J. phys. Oceanogr, 11 (3), 324-336.

Le Dimet, F., and O. Talagrand, 1986: Variational algorithms for analysis and assimilation of meteorological observations: theoretical aspects. Tellus A, 38 (2), 97-110. 
Le Hénaff, M., V. Kourafalou, Y. Morel, and A. Srinivasan, 2012: Simulating the dynamics and intensification of cyclonic Loop Current Frontal Eddies in the Gulf of Mexico. Journal of Geophysical Research, 117 (C2), C02 034.

Leben, R., 2005: Altimeter-derived loop current metrics. Geophysical Monograph-American Geophysical Union, 161, 181.

Lorenc, A., 2003: The potential of the Ensemble Kalman Filter for NWPa comparison with 4DVar. Q. J. R. Meteorol. Soc., 129, 3183-3202.

Marshall, J., A. Adcroft, C. Hill, L. Perelman, and C. Heisey, 1997: A finite-volume, incompressible Navier Stokes model for studies of the ocean on parallel computers. J. Geophys. Res, 102 (C3), 5753-5766.

Mazloff, M., P. Heimbach, and C. Wunsch, 2010: An Eddy-Permitting Southern Ocean State Estimate. Journal of Physical Oceanography, 40, 880-899.

Miyoshi, T., Y. Sato, and T. Kadowaki, 2010: Ensemble Kalman Filter and 4D-Var intercomparison with the Japanese operational global analysis and prediction system. Monthly Weather Review, 138 (7), 2846-2866.

Mogensen, K., M.-A. Balmaseda, A. T. Weaver, M. Martin, and A. Vidard, 2009: NEMOVAR: A variational data assimilation system for the NEMO model. ECMWF Newsletter, Summer Edition.

Moore, A. M., H. G. Arango, G. Broquet, C. Edwards, M. Veneziani, B. Powell, D. Foley, J. D. Doyle, D. Costa, and P. Robinson, 2011a: The Regional Ocean Modeling System (ROMS) 4dimensional variational data assimilation systems: part II-performance and application to the California Current System. Progress in Oceanography, 91 (1), 50-73. 
Moore, A. M., H. G. Arango, G. Broquet, C. Edwards, M. Veneziani, B. Powell, D. Foley, J. D. Doyle, D. Costa, and P. Robinson, 2011b: Regional Ocean Modeling System (ROMS) 4-dimensional variational data assimilation systems Part III-Observation impact and observation sensitivity in the California Current System. Progress in oceanography, 91 (1), 74-94.

Moore, A. M., H. G. Arango, G. Broquet, B. S. Powell, A. T. Weaver, and J. Zavala-Garay, 2011c: The Regional Ocean Modeling System (ROMS) 4-dimensional variational data assimilation systems: Part I-System overview and formulation. Progress in Oceanography, 91 (1), 34-49.

Nerger, L., W. Hiller, and J. Schröter, 2005: The parallel data assimilation framework: experiences with Kalman Filtering. In: W. Zwiefhofer and G. Mozdzynski, Editors, Use of High Performance in Meteorology, Proceedings of the 11th ECMWF Workshop, World Scientific, Singapore, 6386.

Oke, P., G. Brassington, D. Griffin, and A. Schiller, 2008: The Bluelink ocean data assimilation system (BODAS). Ocean Modelling, 21, 46-70.

Pavlis, N. K., S. A. Holmes, S. C. Kenyon, and J. K. Factor, 2012: The development and evaluation of the Earth Gravitational Model 2008 (EGM2008). Journal of Geophysical Research: Solid Earth (1978-2012), 117 (B4).

Pinardi, N., I. Allen, E. Demirov, P. De Mey, G. Korres, A. Lascaratos, P.-Y. Le Traon, C. Maillard, G. Manzella, and C. Tziavos, 2003: The Mediterranean ocean forecasting system: first phase of implementation (1998-2001). Annales Geophysicae, Vol. 21, 3-20.

Rudnick, D., R. Davis, C. Eriksen, D. Fratantoni, and M. Perry, 2004: Underwater gliders for ocean research. Marine Technology Society Journal, 38 (2), 73-84. 
Sakov, P., and P. R. Oke, 2008: Implications of the form of the ensemble transformation in the ensemble square root filters. Monthly Weather Review, 136 (3), 1042-1053.

Schmitz, W., 2003: Notes on the Circulation In and Around the Gulf of Mexico, A Review of the Deep Water Circulation-Vol:1. Harte Research Institute (http://www.harteresearchinstitute. org/whats-news/books/).

Schmitz, W., 2005: Cyclones and westward propagation in the shedding of anticyclonic rings from the Loop Current. Geophysical Monograph-American Geophysical Union, 161, 241.

Sherman, J., R. Davis, W. Owens, and J. Valdes, 2001: The autonomous underwater glider Spray. Oceanic Engineering, IEEE Journal of, 26 (4), 437-446.

Smedstad, O., H. Hurlburt, E. Metzger, R. Rhodes, J. Shriver, A. Wallcraft, and A. Kara, 2003: An operational Eddy resolving 1/16 degrees global ocean nowcast/forecast system. Journal of Marine Systems, 40, 341-361.

Song, H., I. Hoteit, B. D. Cornuelle, and A. C. Subramanian, 2010: An adaptive approach to mitigate background covariance limitations in the Ensemble Kalman Filter. Monthly Weather Review, 138 (7), 2825-2845.

Stammer, D., C. Wunsch, R. Giering, C. Eckert, P. Heimbach, J. Marotzke, A. Adcroft, C. Hill, and J. Marshall, 2002: Global ocean circulation during 1992-1997, estimated from ocean observations and a general circulation model. Journal of Geophysical Research-Oceans, 107 (C9), 3118

Tippett, M., J. Anderson, C. Bishop, T. Hamill, and J. Whitaker, 2003: Ensemble square root filters. Mon. Wea. Rev., 131, 1490-1485. 
Toye, H., P. Zhan, G. Gopalakrishnan, A. R. Kartadikaria, H. Huang, O. Knio, and I. Hoteit, 2017: Ensemble data assimilation in the Red Sea: sensitivity to ensemble selection and atmospheric forcing. Ocean Dynamics, 1-19.

Usui, N., S. Ishizaki, Y. Fujii, H. Tsujino, T. Yasuda, and M. Kamachi, 2006: Meteorological Research Institute multivariate ocean variational estimation (MOVE) system: some early results. Adv. Space Res., 37, 806-822.

Vukovich, F., B. Crissman, M. Bushnell, and W. King, 1979: Some aspects of the oceanography of the Gulf of Mexico using satellite and in situ data. Journal of Geophysical Research, 84 (C12), $7749-7768$.

Vukovich, F., and G. Maul, 1985: Cyclonic eddies in the eastern Gulf of Mexico. Journal of physical Oceanography, 15 (1), 105-117.

Weaver, A., J. Vialard, and D. Anderson, 2003: Three-and four-dimensional variational assimilation with a general circulation model of the tropical Pacific Ocean. Part I: Formulation, internal diagnostics, and consistency checks. Monthly Weather Review, 131 (7), 1360-1378.

Whitaker, J. S., G. P. Compo, and J.-N. Thépaut, 2009: A comparison of variational and ensemblebased data assimilation systems for reanalysis of sparse observations. Monthly Weather Review, 137 (6), 1991-1999.

Wunsch, C., 1996: The ocean circulation inverse problem. Cambridge Univ Pr.

Wunsch, C., and P. Heimbach, 2007: Practical global oceanic state estimation. Physica D, 230, 197-208. 
Yang, S.-C., M. Corazza, A. Carrassi, E. Kalnay, and T. Miyoshi, 2009: Comparison of Local Ensemble Transform Kalman Filter, 3DVAR, and 4DVAR in a quasigeostrophic model. Monthly Weather Review, 137 (2), 693-709.

Zhang, X., B. Cornuelle, and D. Roemmich, 2011: Adjoint Sensitivity of the Niño-3 Surface Temperature to Wind Forcing. Journal of Climate, 24, 4480-4493.

Zubrow, A., L. Chen, and V. Kotamarthi, 2008: EAKF-CMAQ: Introduction and evaluation of a data assimilation for CMAQ based on the Ensemble Adjustment Kalman Filter. Journal of Geophysical Research, 113 (D9), D09 302. 
${ }_{953}$ LIST OF TABLES

${ }_{954}$ Table 1. MITgcm-IAS Model Description . . . . . . . . . . . . . . . . . . 46

955 Table 2. MITgem-IAS Model Forcings _. . . . . . . . . . . . . . . . . . . 47

${ }_{956}$ Table 3. Observations for 2010 experiment $\quad$. . . . . . . . . . . . . . . . . . . . 48

957 Table 4. Details of the MITgcm-DART EnKF assimilation and forecast experiments _. . . 49

${ }_{958}$ Table 5. Details of the MITgcm-ECCO 4DVAR assimilation and forecast experiments . . 50 
TABLE 1: MITgem-IAS Model Description

\begin{tabular}{|c|c|}
\hline Description & Value/Source \\
\hline Longitude & $98^{\circ} \mathrm{W}-72.5^{\circ} \mathrm{W}$ \\
\hline Latitude & $8.5^{\circ} \mathrm{N}-31^{\circ} \mathrm{N}$ \\
\hline Topography & $\begin{array}{l}\text { Two-minute gridded global topography (ETOPO-2), with maxi- } \\
\text { mum depth of } 6000 \mathrm{~m} \text {. }\end{array}$ \\
\hline Horizontal grid & $1 / 10^{\circ} \times 1 / 10^{\circ}(\sim 11 \mathrm{~km})$ spherical polar grid. \\
\hline Vertical grid & $\begin{array}{l}40 \text { vertical } z \text { - levels, with level spacing gradually increasing with } \\
\text { depth from } 5 \mathrm{~m} \text { at the surface to a maximum of } 500 \mathrm{~m} \text { near the } \\
\text { bottom. }\end{array}$ \\
\hline $\begin{array}{l}\text { Sub-grid scale parame- } \\
\text { terization }\end{array}$ & Vertical, second order diffusive operator. \\
\hline $\begin{array}{l}\text { Vertical diffusivity and } \\
\text { viscosity parameteriza- } \\
\text { tion }\end{array}$ & $\begin{array}{l}\text { Laplacian mixing with a background value of } 1 \times 10^{-6} \mathrm{~m}^{2} \mathrm{~s}^{-1} \\
\text { and } 1 \times 10^{-4} \mathrm{~m}^{2} \mathrm{~s}^{-1} \text {, respectively, and the K-profile parameteri- } \\
\text { zation (KPP) in the surface mixed layer (Large et al. 1994). }\end{array}$ \\
\hline $\begin{array}{l}\text { Horizontal diffusivity } \\
\text { and viscosity (second } \\
\text { order) }\end{array}$ & $1 \times 10^{2} \mathrm{~m}^{2} \mathrm{~s}^{-1}$ \\
\hline $\begin{array}{l}\text { Horizontal diffusivity } \\
\text { and viscosity (fourth } \\
\text { order) }\end{array}$ & $1 \times 10^{11} \mathrm{~m}^{4} \mathrm{~s}^{-1}$ \\
\hline
\end{tabular}


TABLE 2: MITgem-IAS Model Forcings

\begin{tabular}{ll}
\hline Description & Source \\
\hline Initial conditions & $\begin{array}{l}\text { The Hybrid Coordinate Ocean Model (HYCOM) global } \\
1 / 12^{\circ} \text { daily analysis (http://hycom. org/dataserver/ } \\
\text { glb-analysis) using Navy Coupled Ocean Data Assimilation } \\
\text { (NCODA)(Chassignet et al. 2007). }\end{array}$ \\
\hline
\end{tabular}

Open boundary (OB) HYCOM/NCODA global $1 / 12^{\circ}$ estimates of T, S, and horizonconditions tal velocities (U: east - west and V: north - south components), sampled every 7 days.

OB sponge layer $\quad$ Buffer zone of $1^{\circ}$, with restoring time scales varying linearly from 1 day at the boundary to 5 days at the inner edge of the sponge layers. HYCOM/NCODA normal velocity fields across the OB have been adjusted to have zero net volume flux into the model domain.

Atmospheric forcing National Centers for Environmental Prediction (NCEP)/National Center for Atmospheric Research (NCAR) re-analysis (NCEP/NCAR-R1) project (Kalnay et al. 1996).

Atmospheric state

Bulk formulation (Large and Pond 1981) for the computation of the atmospheric fluxes. The atmospheric forcing includes $2^{\circ} \times 2^{\circ}$ global gridded air temperature, specific humidity, zonal and meridional wind speed at $10 \mathrm{~m}$ from the ground, total precipitation, and short and long wave radiative fluxes, sampled every 6 hours.

Run-off fluxes

Monthly climatological freshwater fluxes from the ECCO global model (Stammer et al. 2002). 
TABLE 3: Observations for 2010 experiment

\begin{tabular}{|c|c|c|}
\hline Data type & Description & Source \\
\hline $\begin{array}{l}\text { Mean } \\
\text { Dynamic } \\
\text { Topogra- } \\
\text { phy (MDT) }\end{array}$ & $\begin{array}{l}\text { Danish National Space Center Mean Sea Sur- } \\
\text { face } 2008 \text { (DNSCMSS08) minus Earth Gravity } \\
\text { Model } 2008 \text { (EGM08): DNSCMSS08-EGM08. }\end{array}$ & $\begin{array}{l}\text { (Andersen and Knudsen } \\
\text { 2009; Pavlis et al. 2012) }\end{array}$ \\
\hline Altimetry & $\begin{array}{l}\text { Along-track Sea Surface Height (SSH) anoma- } \\
\text { lies from three satellites: Jason-1 (J1), Jason- } \\
2 \text { (J2), and Envisat (N1) with respect to } \\
\text { DNSCMSS08-EGM08 MDT. }\end{array}$ & $\begin{array}{l}\text { Radar Altimetry } \begin{array}{l}\text { Database } \\
\text { (RADS), }\end{array} \\
\text { (http: //rads.tudelft. } \\
\text { nl/rads/index.shtml) }\end{array}$ \\
\hline $\begin{array}{l}\text { Sea- } \\
\text { Surface } \\
\text { Tempera- } \\
\text { ture (SST) }\end{array}$ & $\begin{array}{l}\text { Daily, optimally interpolated product from the } \\
\text { TMI/AMSR-E instruments on a } 0.25^{\circ} \times 0.25^{\circ} \\
\text { grid. }\end{array}$ & $\begin{array}{l}\text { Remote Sensing Systems Inc. } \\
\text { (http: //www.remss. com/) }\end{array}$ \\
\hline $\begin{array}{l}\text { Spray } \\
\text { glider } \\
\text { (Non- } \\
\text { assimilated } \\
\text { data, used } \\
\text { only for } \\
\text { model } \\
\text { forecast } \\
\text { validation) }\end{array}$ & Temperature and Salinity profiles. & $\begin{array}{l}\text { SIO Spray glider (Sher- } \\
\text { man et al. 2001; Rudnick } \\
\text { et al. 2004) data server } \\
\text { (http://spraydata.ucsd. } \\
\text { edu/projects/GoM) }\end{array}$ \\
\hline
\end{tabular}


TABLE 4: Details of the MITgcm-DART EnKF assimilation and forecast experiments

\begin{tabular}{|c|c|c|c|c|c|c|}
\hline & Experiment & $\begin{array}{l}\text { Ensemble】 } \\
\text { size }\end{array}$ & $\begin{array}{l}\text { Localization】 } \\
\text { radius }\end{array}$ & Inflation & Hindcast & Forecast \\
\hline & & & $(\mathrm{km})$ & & & \\
\hline & $\begin{array}{l}\text { EnKF2010-N50- } \\
\text { I1.2-L250 }\end{array}$ & 50 & 250 & 1.2 & $\begin{array}{l}2 \text { months } \\
(03 / 01-04 / 29)\end{array}$ & $\begin{array}{l}2 \text { months } \\
(04 / 30-06 / 28)\end{array}$ \\
\hline & $\begin{array}{l}\text { EnKF2010-N50- } \\
\text { I1.2-L500 }\end{array}$ & 50 & 500 & 1.2 & $\begin{array}{l}2 \text { months } \\
(03 / 01-04 / 29)\end{array}$ & $\begin{array}{l}2 \text { months } \\
(04 / 30-06 / 28)\end{array}$ \\
\hline$\stackrel{\circ}{\circ}$ & $\begin{array}{l}\text { EnKF2010-N50- } \\
\text { I1.3-L500 }\end{array}$ & 50 & 500 & 1.3 & $\begin{array}{l}2 \text { months } \\
(03 / 01-04 / 29)\end{array}$ & $\begin{array}{l}2 \text { months } \\
(04 / 30-06 / 28)\end{array}$ \\
\hline & $\begin{array}{l}\text { EnKF2010- } \\
\text { N100-I1.2-L500 }\end{array}$ & 100 & 500 & 1.2 & $\begin{array}{l}2 \text { months } \\
(03 / 01-04 / 29)\end{array}$ & $\begin{array}{l}2 \text { months } \\
(04 / 30-06 / 28)\end{array}$ \\
\hline & $\begin{array}{l}\text { EnKF2010-N25- } \\
\text { I1.2-L250-2MN }\end{array}$ & 25 & 250 & 1.2 & $\begin{array}{l}2 \text { months } \\
(03 / 01-04 / 29)\end{array}$ & $\begin{array}{l}2 \text { months } \\
(04 / 30-06 / 28)\end{array}$ \\
\hline & $\begin{array}{l}\text { EnKF2010-N25- } \\
\text { I1.2-L500 }\end{array}$ & 25 & 500 & 1.2 & $\begin{array}{l}2 \text { months } \\
(03 / 01-04 / 29)\end{array}$ & $\begin{array}{l}2 \text { months } \\
(04 / 30-06 / 28)\end{array}$ \\
\hline & $\begin{array}{l}\text { EnKF2010-N25- } \\
\text { I1.2-L250-1MN }\end{array}$ & 25 & 250 & 1.2 & $\begin{array}{l}1 \text { month } \\
(03 / 31-04 / 29)\end{array}$ & $\begin{array}{l}2 \text { months } \\
(04 / 30-06 / 28)\end{array}$ \\
\hline & $\begin{array}{l}\text { EnKF2010-N25- } \\
\text { I1.2-L250-2WK }\end{array}$ & 25 & 250 & 1.2 & $\begin{array}{l}2 \text { weeks } \\
(04 / 15-04 / 29)\end{array}$ & $\begin{array}{l}2 \text { months } \\
(04 / 30-06 / 28)\end{array}$ \\
\hline ঠ্ণ & $\begin{array}{l}\text { EnKF2006-N25- } \\
\text { I1.2-L125 }\end{array}$ & 25 & 250 & 1.2 & $\begin{array}{l}2 \text { months } \\
(07 / 01-08 / 29)\end{array}$ & $\begin{array}{l}2 \text { months } \\
(08 / 30-10 / 28)\end{array}$ \\
\hline & $\begin{array}{l}\text { EnKF2006- } \\
\text { N100-I1.2-L125 }\end{array}$ & 100 & 250 & 1.2 & $\begin{array}{l}2 \text { months } \\
(07 / 01-08 / 29)\end{array}$ & $\begin{array}{l}2 \text { months } \\
(08 / 30-10 / 28)\end{array}$ \\
\hline$\stackrel{m}{\stackrel{2}{2}}$ & $\begin{array}{l}\text { EnKF2013-N25- } \\
\text { I1.2-L125 }\end{array}$ & 25 & 250 & 1.2 & $\begin{array}{l}2 \text { months } \\
(01 / 01-03 / 01)\end{array}$ & $\begin{array}{l}2 \text { months } \\
(03 / 02-04 / 30)\end{array}$ \\
\hline$\frac{d}{8}$ & $\begin{array}{l}\text { EnKF2014-N25- } \\
\text { I1.2-L125 }\end{array}$ & 25 & 250 & 1.2 & $\begin{array}{l}1 \text { month } \\
(02 / 01-02 / 27)\end{array}$ & $\begin{array}{l}2 \text { months } \\
(02 / 28-04 / 28)\end{array}$ \\
\hline
\end{tabular}

${ }^{*}$ The MITgcm-DART experiments are named as: EnKF $<$ year $>-<\mathrm{N}$ : ensemble size $>-<\mathrm{I}$ : inflation factor $>-<\mathrm{L}$ : localization radius in $\mathrm{km}>$

* Month is abbreviated as MN, and week is abbreviated as WK 
TABLE 5: Details of the MITgem-ECCO 4DVAR assimilation and forecast experiments

\begin{tabular}{|c|c|c|c|}
\hline & Experiment & Hindcast & Forecast \\
\hline$\stackrel{\circ}{\circ}$ & 4DVAR-2010 & $\begin{array}{l}2 \text { months } \\
(03 / 01-04 / 29)\end{array}$ & $\begin{array}{l}2 \text { months } \\
(04 / 30-06 / 28)\end{array}$ \\
\hline ঠ্ণ & 4DVAR-2006 & $\begin{array}{l}2 \text { months } \\
(07 / 01-08 / 29)\end{array}$ & $\begin{array}{l}2 \text { months } \\
(08 / 30-10 / 28)\end{array}$ \\
\hline$\stackrel{m}{\check{n}}$ & 4DVAR-2013 & $\begin{array}{l}2 \text { months } \\
(01 / 01-03 / 01)\end{array}$ & $\begin{array}{l}2 \text { months } \\
(03 / 02-04 / 30)\end{array}$ \\
\hline$\frac{\text { d }}{8}$ & 4DVAR-2014 & $\begin{array}{l}1 \text { month } \\
(02 / 01-02 / 27)\end{array}$ & $\begin{array}{l}2 \text { months } \\
(02 / 28-04 / 28)\end{array}$ \\
\hline
\end{tabular}




\section{LIST OF FIGURES}

Fig. 1. Observations for 2010 experiment: Top panel (a) shows the spatial coverage of TMI/AMSRE SST data, where the colors represent the temporal mean of SST data over the two-month assimilation (March 1 - April 29, 2010) period. Spray glider trajectories (only in June 2010), marked in magenta circles, were used for model forecast assessment. The bottom panel (b) shows the superposed satellite ground tracks from Jason-1 (red), Jason-2 (blue), and Envisat (green) for the same period. The coastline is marked by a black solid line, while gray contour lines show bottom topography for $500 \mathrm{~m}, 1000 \mathrm{~m}, 2000 \mathrm{~m}, 3000 \mathrm{~m}$, and $6000 \mathrm{~m}$. The black star indicates the location of the DwH oil spill in the GoM on April 20, 2010. Thick blue line represents the spatial domain for the hindcast and forecast model-data rmsd computation.

Fig. 2. SSH fields at the start date of the assimilation period (Hindcast): The top left panel (a) shows ensemble mean analysis (MIT-EnKF-A), and the bottom left panel (d) shows ensemble mean forecast (MIT-EnKF-F). The top middle panel (b) shows optimized model state from MITgem-ECCO 4DVAR (MIT-4DVAR, from iteration 14), and the bottom middle panel (e) shows the control "first-guess" solution (MIT-C, from iteration 1). The top right panel (c) shows the AVISO gridded SSH field, and the bottom right panel (f) shows assimilated HYCOM/NCODA global daily analysis (HYCOM-GLOBAL). The surface currents for MIT-EnKF-A, MIT-EnKF-F, MIT-4DVAR, MIT-C, and HYCOM-GLOBAL are shown by black vectors and green vectors where current speed exceeds $85 \mathrm{~cm} \mathrm{~s}^{-1}$. The black solid line contour marks the $17 \mathrm{~cm} \mathrm{SSH}$ contour. The black star shows the location of the DwH oil spill in the GoM. The MITgcm-DART EnKF assimilation used filter parameters of EnKF2010-N50-I1.2-L250 (refer Table 4).

Fig. 3. SSH fields at the end date of the assimilation period (Hindcast). Figure caption remain the same as Figure 2.

Fig. 4. SST fields at the end date of the assimilation period (Hindcast): The top left panel (a) shows ensemble mean analysis (MIT-EnKF-A), and the bottom left panel (d) shows ensemble mean forecast (MIT-EnKF-F). The top middle panel (b) shows optimized model state from MITgcm-ECCO 4DVAR (MIT-4DVAR, from iteration 14), and the bottom middle panel (e) shows the control "first-guess" solution (MIT-C, from iteration 1). The top right panel (c) shows the TMI/AMSR-E gridded SST field, and the bottom right panel (f) shows assimilated HYCOM/NCODA global daily analysis (HYCOM-GLOBAL). The black star shows the location of the DwH oil spill in the GoM. The MITgcm-DART EnKF assimilation used filter parameters of EnKF2010-N50-I1.2-L250 (refer Table 4).

Fig. 5. SSH model-data $r m s d$ for hindcasts: The top panel shows the rmsd for MITgcm-ECCO solutions, for optimized solution (MIT-4DVAR, from iteration 14), control solution (MIT-C, from iteration 1), model persistence (MIT-P, keeping the MIT-4DVAR initial state fixed), and HYCOM/NCODA global daily analysis (HYCOM-GLOBAL). The bottom panel shows the rmsd for MITgcm-DART solutions, for ensemble mean analysis (MIT-EnKF-A), ensemble mean forecast (MIT-EnKF-F), model persistence (MIT-P, keeping the MIT-EnKF-A initial state fixed), and HYCOM/NCODA global daily analysis (HYCOM-GLOBAL). The modeldata rmsd is computed with respect to the AVISO gridded SSH data, over the GoM spatial domain highlighted by the blue curve in Figure 1. The MITgcm-DART EnKF assimilation used filter parameters of EnKF2010-N50-I1.2-L250 (refer Table 4). Additional dashed thick lines marks the ensemble spread averaged over the spatial domain highlighted by the blue curve in Figure 1 for analysis and forecast, and dashed thin lines marks the total error (ensemble spread + observation error of $5 \mathrm{~cm}$ ) for both analysis and forecast. 
Fig. 6. SSH fields at the end of first month of the two-month model forecast: The top left panel (a) shows forecast initialized using the ensemble mean analysis (MIT-EnKF-Ens) from the last assimilation cycle of the MITgcm-DART EnKF system, and the bottom left panel (d) shows mean of ensemble forecast (MIT-EnKF-Ave) initialized using the analysis of each ensemble member of the last assimilation cycle. The top middle panel (b) shows forecast initialized from the end of the optimized state from MITgcm-ECCO 4DVAR system (MIT4DVAR, from iteration 14), and the bottom middle panel (e) shows the control forecast initialized using HYCOM/NCODA global daily analysis for the forecast start date. The top right panel (c) shows the AVISO gridded SSH field, and the bottom right panel (f) shows assimilated HYCOM/NCODA global daily analysis (HYCOM-GLOBAL). The surface currents for MIT-EnKF-Ens, MIT-EnKF-Ave, MIT-4DVAR, MIT-C, and HYCOM-GLOBAL are shown by black vectors and green vectors where current speed exceeds $85 \mathrm{~cm} \mathrm{~s}^{-1}$. The black solid line contour marks the $17 \mathrm{~cm} \mathrm{SSH} \mathrm{contour.} \mathrm{The} \mathrm{black} \mathrm{star} \mathrm{shows} \mathrm{the} \mathrm{location} \mathrm{of}$ the DwH oil spill in the GoM. The MITgcm-DART EnKF assimilation used filter parameters of EnKF2010-N50-I1.2-L250 (refer Table 4).

Fig. 7. Model comparison with glider data for June 2010: The first column of panels show glider data, second column of panels shows difference between glider data and MIT-4DVAR forecast (data - MIT-4DVAR), third column of panels show difference between glider data and MIT-C forecast initialized using HYCOM/NCODA global daily analysis, fourth column of panels show between glider data and model forecast initialized using ensemble mean analysis at the end of hindcast period (data - MIT-EnKF-Ens), and the last column of panels show difference between glider data and the mean of ensemble forecast (data - MIT-EnKF-Ave). The top row of panels are for temperature and bottom row of panels are for salinity. The anomaly root-mean-square-difference $\left(r m s d_{a}\right)$ and anomaly correlation coefficient $\left(c c_{a}\right)$ for each case are labeled. The MITgcm-DART EnKF assimilation used filter parameters of EnKF2010-N50-I1.2-L250 (refer Table 4).

Fig. 8. Top panel: SSH rmsd with respect to AVISO analysis for MITgcm-DART ensemble forecast: The gray curves (Ens) show rmsd from each ensemble member, red curve (MITEnKF-Ens) shows forecast from ensemble mean analysis, green curve (MIT-EnKF-Ave) shows the mean of the ensemble forecast, black curve (MIT-C) shows the control forecast initialized using HYCOM/NCODA global daily analysis, golden curve shows HYCOMGLOBAL analysis, purple curve shows the forecast from MITgcm-ECCO optimized state (MIT-4DVAR), dashed purple curve shows persistence forecast for MIT-4DVAR, and dashed red curve shows persistence forecast for MIT-EnKF-Ens. Bottom panel: The northward extent of the LC index computed by tracking the $17 \mathrm{~cm} \mathrm{SSH}$ isoline obtained from the model solutions (MIT-EnKF-Ens, MIT-EnKF-Ave, Ens, MIT-4DVAR) and AVISO analysis by following the procedure provided in Leben (2005). The MITgcm-DART EnKF assimilation used filter parameters of EnKF2010-N50-I1.2-L250 (refer Table 4).

Fig. 9. The evolution of the LC based on $17 \mathrm{~cm} \mathrm{SSH}$ contour for the days 1, 14, 21, and 28 of the two-month ensemble forecasts. The gray curves (Ens) show ensemble members, the red curve (MIT-EnKF-Ens) shows forecast initialized using ensemble mean analysis, the green curve (MIT-EnKF-Ave) shows the mean of the ensemble forecast, and the cyan curve shows AVISO analysis. The MITgcm-DART EnKF assimilation used filter parameters of EnKF2010-N50-I1.2-L250 (refer Table 4).

Fig. 10. SSH standard deviation (top four panels) and mean (bottom four panels) for the days 1, 14, 21, and 28 of the two-month ensemble forecasts. The MITgcm-DART EnKF assimilation used filter parameters of EnKF2010-N50-I1.2-L250 (refer Table 4). 
Fig. 11. The MITgcm-DART EnKF filter parameter sensitivity experiments. The top left panel shows sensitivity to ensemble size. The top right panel shows sensitivity to covariance inflation factor. The bottom left panel shows sensitivity to localization length scale. The bottom right panel shows sensitivity to number of assimilation cycles (hindcast period). The MITgcmDART EnKF and MITgcm-ECCO 4DVAR experiments are summarized in Table 4 and Table 5 , respectively.

Fig. 12. SSH rmsd with respect to AVISO analysis for MITgem-ECCO and MITgcm-DART hindcast and forecast experiments for 2006 (top panel), 2013 (middle panel), and 2014 (bottom panel). The golden curve shows HYCOM-GLOBAL analysis, purple curve shows the forecast from MITgcm-ECCO optimized state (MIT-4DVAR), and black curve (MIT-C) shows the control forecast initialized using HYCOM/NCODA global daily analysis for the forecast start date. The blue and green curves shows forecast from ensemble mean analysis, with and their respective means of ensemble forecasts marked by dashed curves. The MITgcm-DART EnKF and MITgcm-ECCO 4DVAR experiments are summarized in Table 4 and Table 5, respectively. 

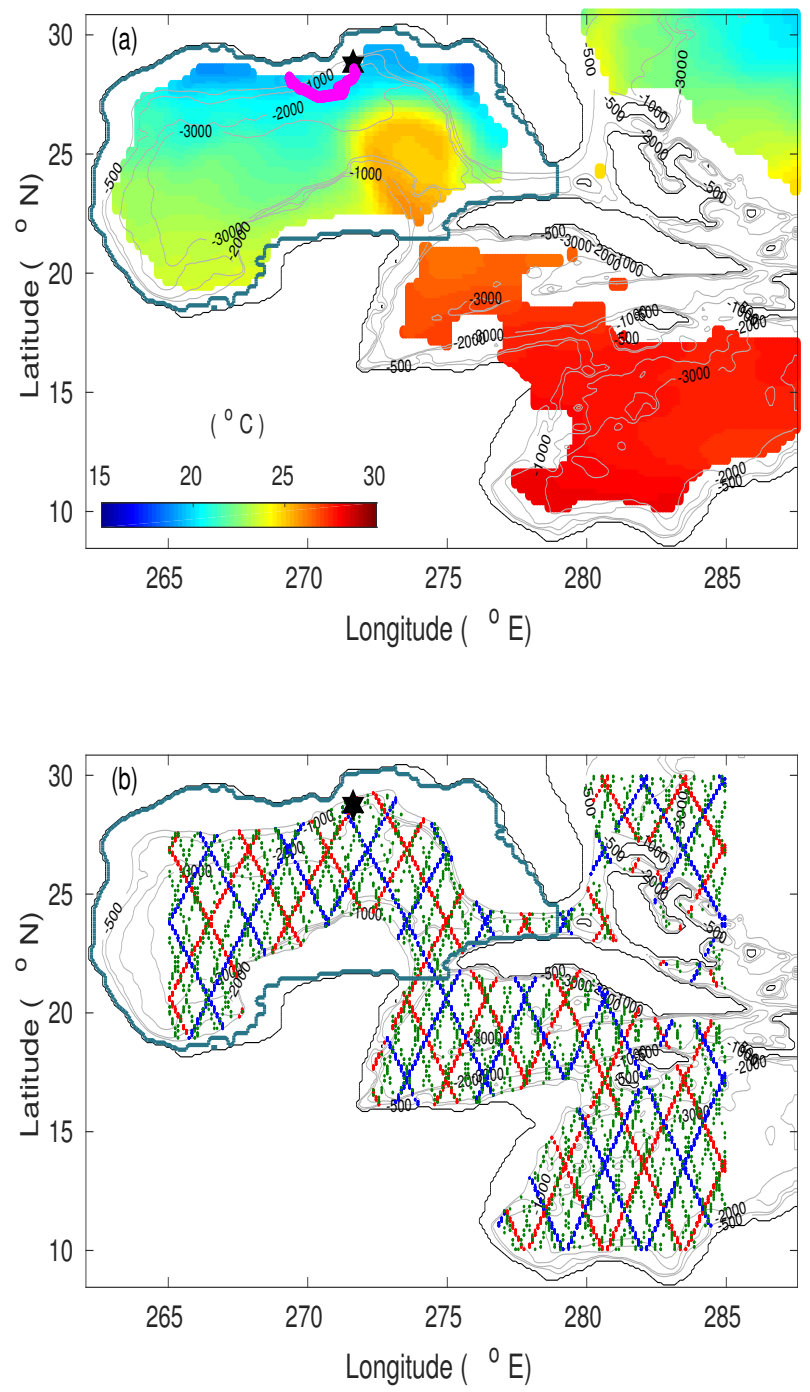

FIG. 1: Observations for 2010 experiment: Top panel (a) shows the spatial coverage of TMI/AMSR-E SST data, where the colors represent the temporal mean of SST data over the two-month assimilation (March 1 - April 29, 2010) period. Spray glider trajectories (only in June 2010), marked in magenta circles, were used for model forecast assessment. The bottom panel (b) shows the superposed satellite ground tracks from Jason-1 (red), Jason-2 (blue), and Envisat (green) for the same period. The coastline is marked by a black solid line, while gray contour lines show bottom topography for $500 \mathrm{~m}, 1000 \mathrm{~m}, 2000 \mathrm{~m}, 3000 \mathrm{~m}$, and $6000 \mathrm{~m}$. The black star indicates the location of the DwH oil spill in the GoM on April 20, 2010. Thick blue line represents the spatial domain for the hindcast and forecast model-data rmsd computation. 

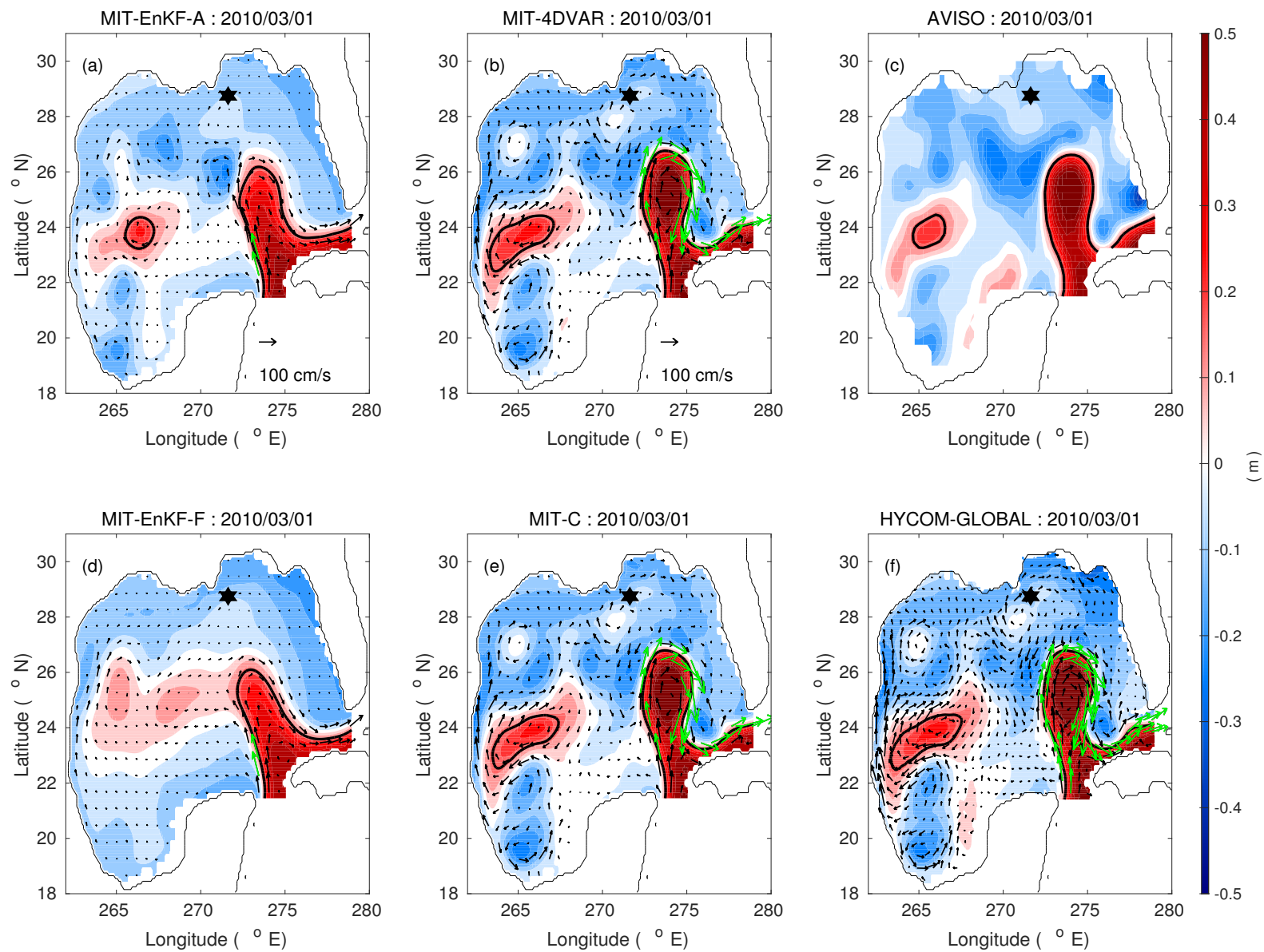

FIG. 2: SSH fields at the start date of the assimilation period (Hindcast): The top left panel (a) shows ensemble mean analysis (MIT-EnKF-A), and the bottom left panel (d) shows ensemble mean forecast (MIT-EnKF-F). The top middle panel (b) shows optimized model state from MITgcm-ECCO 4DVAR (MIT-4DVAR, from iteration 14), and the bottom middle panel (e) shows the control "first-guess" solution (MIT-C, from iteration 1). The top right panel (c) shows the AVISO gridded SSH field, and the bottom right panel (f) shows assimilated HYCOM/NCODA global daily analysis (HYCOM-GLOBAL). The surface currents for MIT-EnKF-A, MIT-EnKFF, MIT-4DVAR, MIT-C, and HYCOM-GLOBAL are shown by black vectors and green vectors where current speed exceeds $85 \mathrm{~cm} \mathrm{~s}^{-1}$. The black solid line contour marks the $17 \mathrm{~cm} \mathrm{SSH} \mathrm{con-}$ tour. The black star shows the location of the DwH oil spill in the GoM. The MITgcm-DART EnKF assimilation used filter parameters of EnKF2010-N50-I1.2-L250 (refer Table 4). 

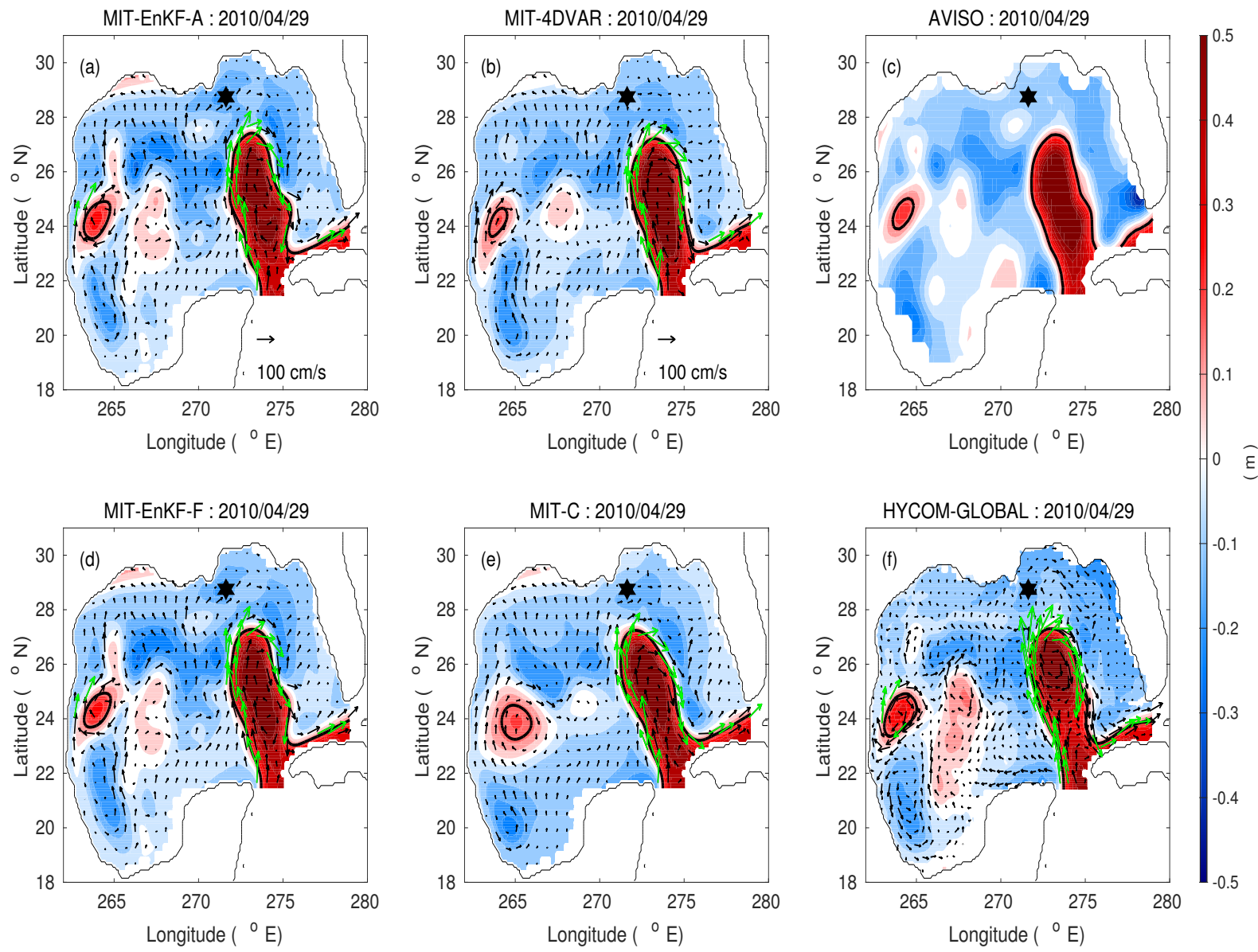

FIG. 3: SSH fields at the end date of the assimilation period (Hindcast). Figure caption remain the same as Figure 2. 

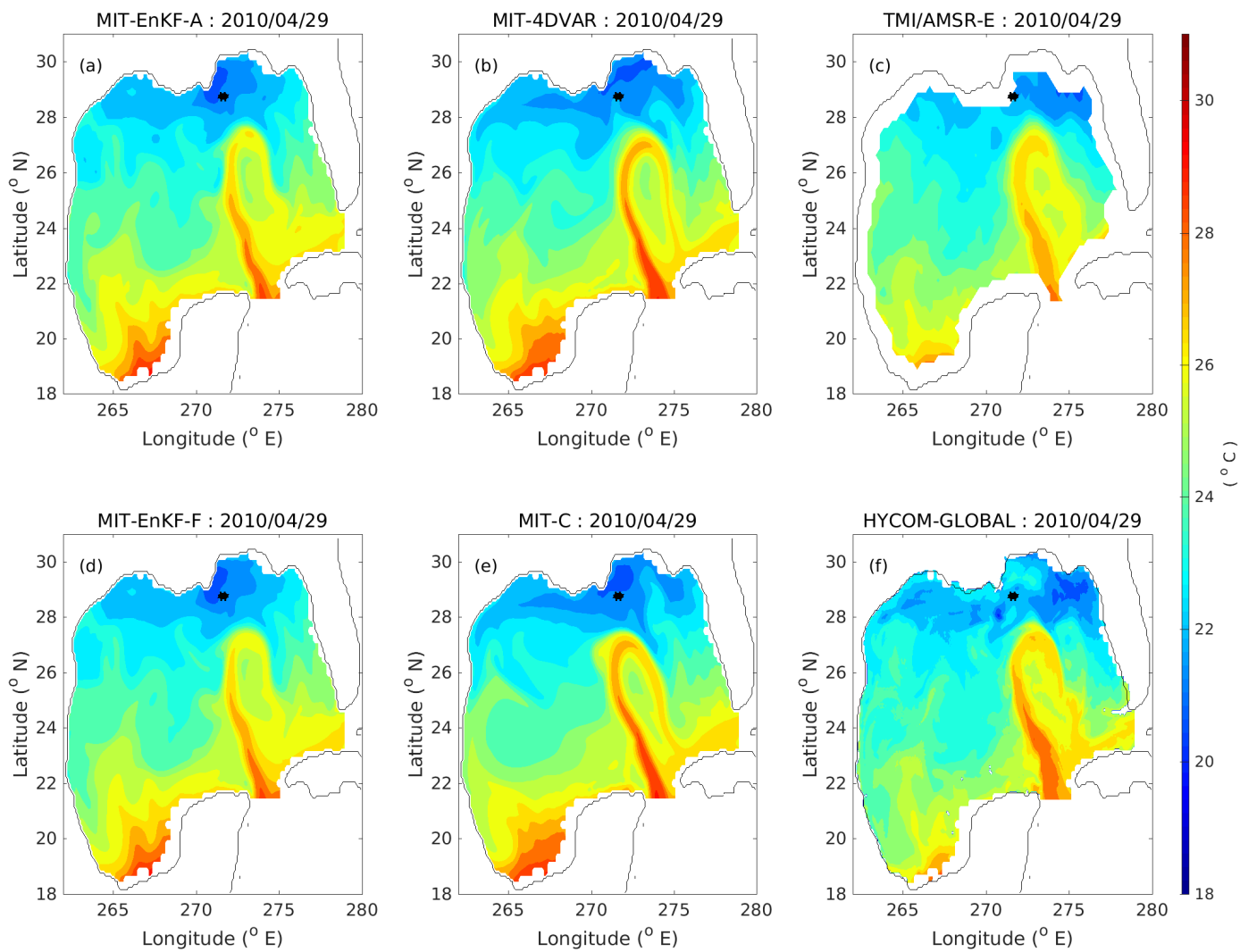

FIG. 4: SST fields at the end date of the assimilation period (Hindcast): The top left panel (a) shows ensemble mean analysis (MIT-EnKF-A), and the bottom left panel (d) shows ensemble mean forecast (MIT-EnKF-F). The top middle panel (b) shows optimized model state from MITgcm-ECCO 4DVAR (MIT-4DVAR, from iteration 14), and the bottom middle panel (e) shows the control "first-guess" solution (MIT-C, from iteration 1). The top right panel (c) shows the TMI/AMSR-E gridded SST field, and the bottom right panel (f) shows assimilated HYCOM/NCODA global daily analysis (HYCOM-GLOBAL). The black star shows the location of the DwH oil spill in the GoM. The MITgcm-DART EnKF assimilation used filter parameters of EnKF2010-N50-I1.2-L250 (refer Table 4). 


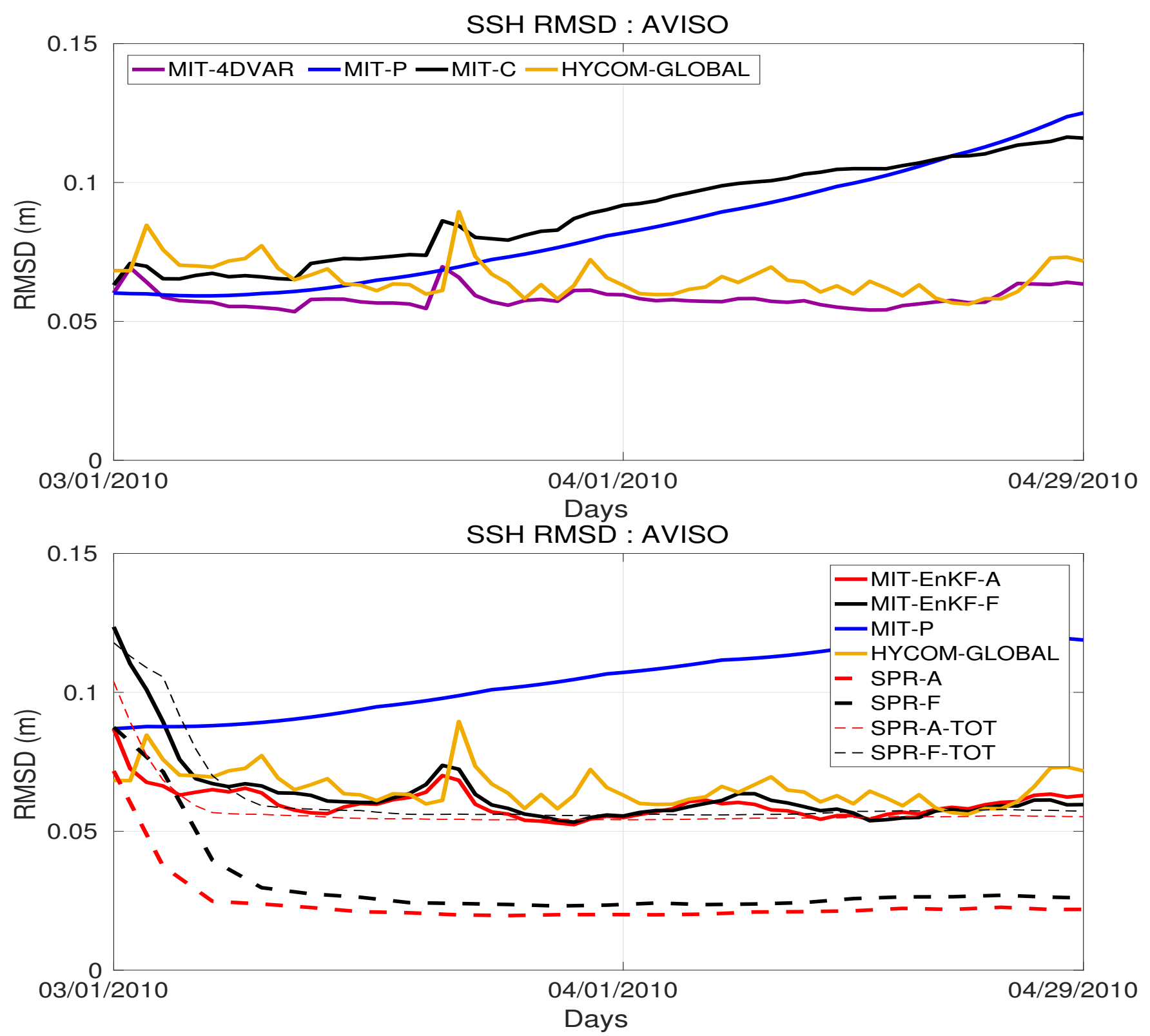

FIG. 5: SSH model-data rmsd for hindcasts: The top panel shows the rmsd for MITgcm-ECCO solutions, for optimized solution (MIT-4DVAR, from iteration 14), control solution (MIT-C, from iteration 1), model persistence (MIT-P, keeping the MIT-4DVAR initial state fixed), and HYCOM/NCODA global daily analysis (HYCOM-GLOBAL). The bottom panel shows the rmsd for MITgcm-DART solutions, for ensemble mean analysis (MIT-EnKF-A), ensemble mean forecast (MIT-EnKF-F), model persistence (MIT-P, keeping the MIT-EnKF-A initial state fixed), and HYCOM/NCODA global daily analysis (HYCOM-GLOBAL). The model-data rmsd is computed with respect to the AVISO gridded SSH data, over the GoM spatial domain highlighted by the blue curve in Figure 1. The MITgcm-DART EnKF assimilation used filter parameters of EnKF2010N50-I1.2-L250 (refer Table 4). Additional dashed thick lines marks the ensemble spread averaged over the spatial domain highlighted by the blue curve in Figure 1 for analysis and forecast, and dashed thin lines marks the total error (ensemble spread + observation error of $5 \mathrm{~cm}$ ) for both analysis and forecast. 

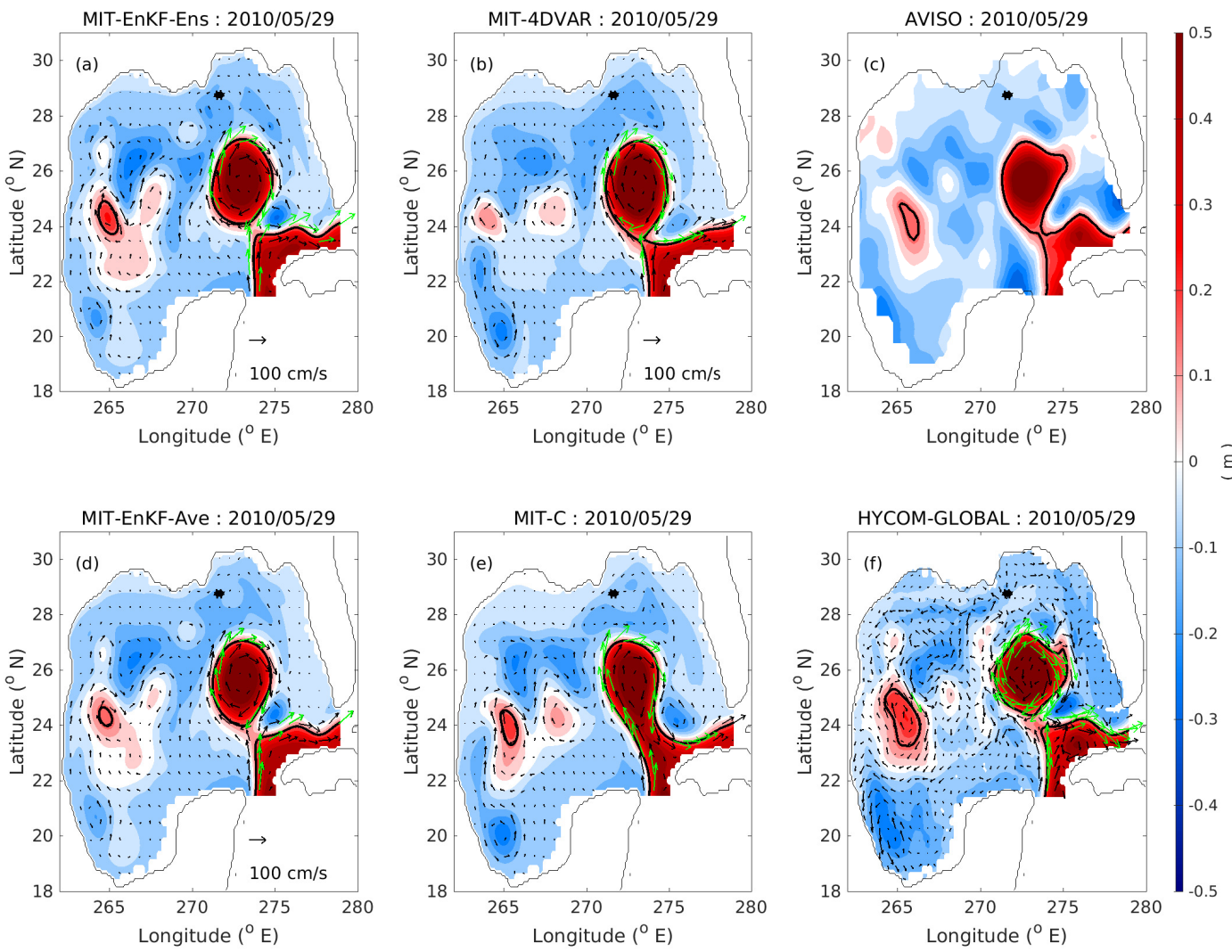

FIG. 6: SSH fields at the end of first month of the two-month model forecast: The top left panel (a) shows forecast initialized using the ensemble mean analysis (MIT-EnKF-Ens) from the last assimilation cycle of the MITgcm-DART EnKF system, and the bottom left panel (d) shows mean of ensemble forecast (MIT-EnKF-Ave) initialized using the analysis of each ensemble member of the last assimilation cycle. The top middle panel (b) shows forecast initialized from the end of the optimized state from MITgcm-ECCO 4DVAR system (MIT-4DVAR, from iteration 14), and the bottom middle panel (e) shows the control forecast initialized using HYCOM/NCODA global daily analysis for the forecast start date. The top right panel (c) shows the AVISO gridded SSH field, and the bottom right panel (f) shows assimilated HYCOM/NCODA global daily analysis (HYCOM-GLOBAL). The surface currents for MIT-EnKF-Ens, MIT-EnKF-Ave, MIT-4DVAR, MIT-C, and HYCOM-GLOBAL are shown by black vectors and green vectors where current speed exceeds $85 \mathrm{~cm} \mathrm{~s}^{-1}$. The black solid line contour marks the $17 \mathrm{~cm} \mathrm{SSH} \mathrm{contour.} \mathrm{The} \mathrm{black} \mathrm{star}$ shows the location of the DwH oil spill in the GoM. The MITgcm-DART EnKF assimilation used filter parameters of EnKF2010-N50-I1.2-L250 (refer Table 4). 

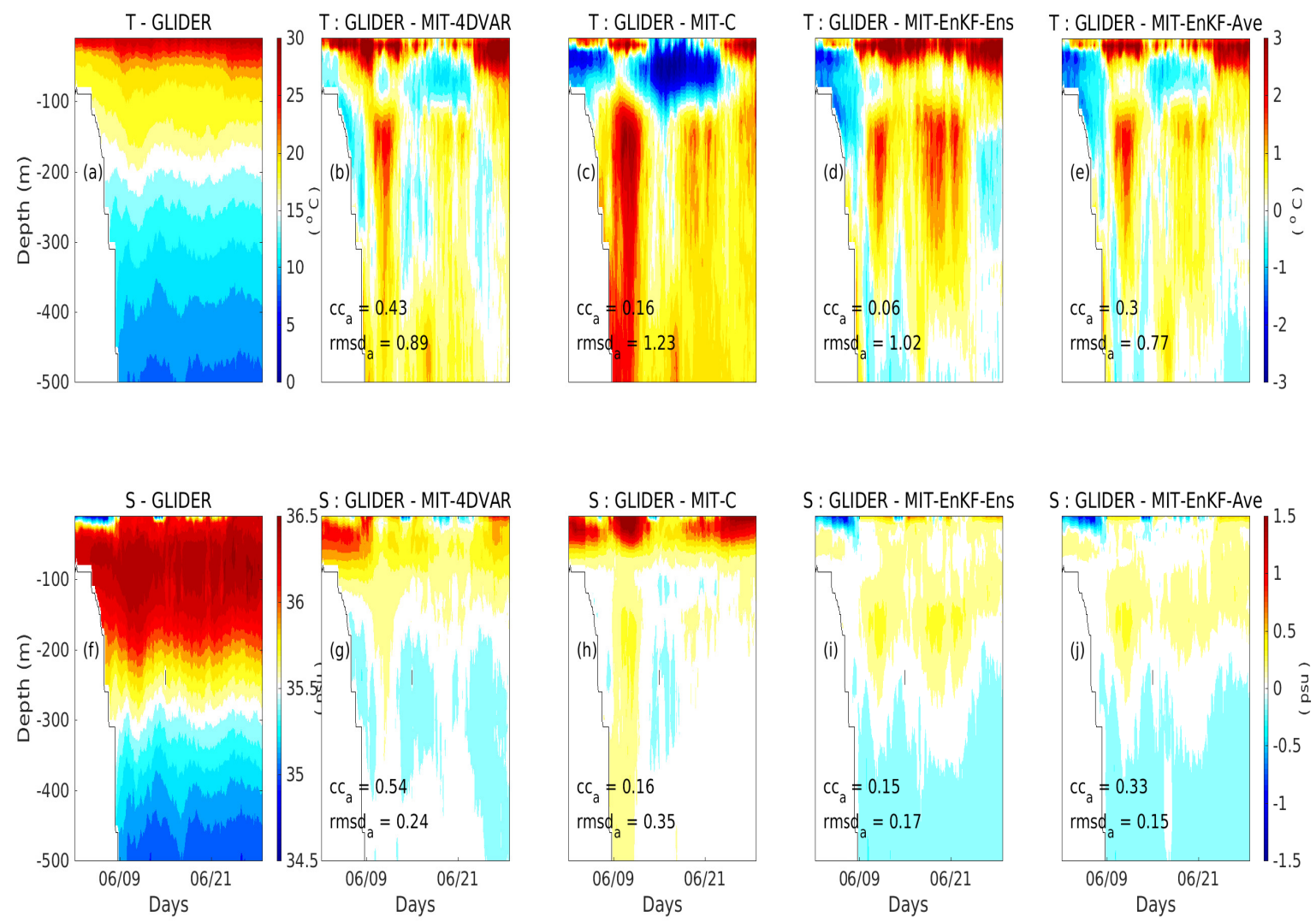

FIG. 7: Model comparison with glider data for June 2010: The first column of panels show glider data, second column of panels shows difference between glider data and MIT-4DVAR forecast (data - MIT-4DVAR), third column of panels show difference between glider data and MIT-C forecast initialized using HYCOM/NCODA global daily analysis, fourth column of panels show between glider data and model forecast initialized using ensemble mean analysis at the end of hindcast period (data - MIT-EnKF-Ens), and the last column of panels show difference between glider data and the mean of ensemble forecast (data - MIT-EnKF-Ave). The top row of panels are for temperature and bottom row of panels are for salinity. The anomaly root-mean-square-difference $\left(r m s d_{a}\right)$ and anomaly correlation coefficient $\left(c c_{a}\right)$ for each case are labeled. The MITgcm-DART EnKF assimilation used filter parameters of EnKF2010-N50-I1.2-L250 (refer Table 4). 


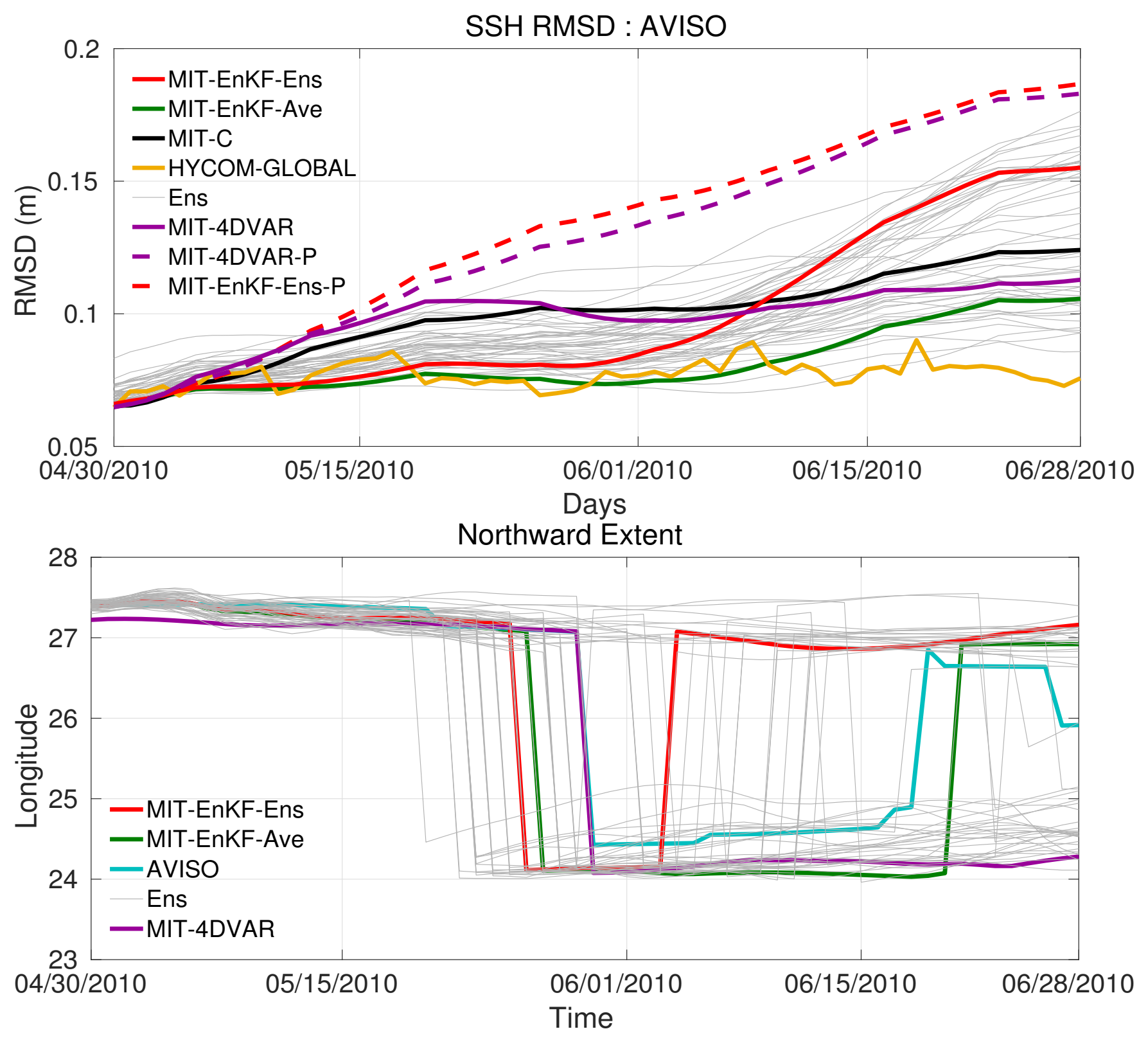

FIG. 8: Top panel: SSH rmsd with respect to AVISO analysis for MITgcm-DART ensemble forecast: The gray curves (Ens) show rmsd from each ensemble member, red curve (MIT-EnKFEns) shows forecast from ensemble mean analysis, green curve (MIT-EnKF-Ave) shows the mean of the ensemble forecast, black curve (MIT-C) shows the control forecast initialized using HYCOM/NCODA global daily analysis, golden curve shows HYCOM-GLOBAL analysis, purple curve shows the forecast from MITgcm-ECCO optimized state (MIT-4DVAR), dashed purple curve shows persistence forecast for MIT-4DVAR, and dashed red curve shows persistence forecast for MIT-EnKF-Ens. Bottom panel: The northward extent of the LC index computed by tracking the $17 \mathrm{~cm} \mathrm{SSH}$ isoline obtained from the model solutions (MIT-EnKF-Ens, MIT-EnKF-Ave, Ens, MIT-4DVAR) and AVISO analysis by following the procedure provided in Leben (2005). The MITgcm-DART EnKF assimilation used filter parameters of EnKF2010-N50-I1.2-L250 (refer Table 4). 

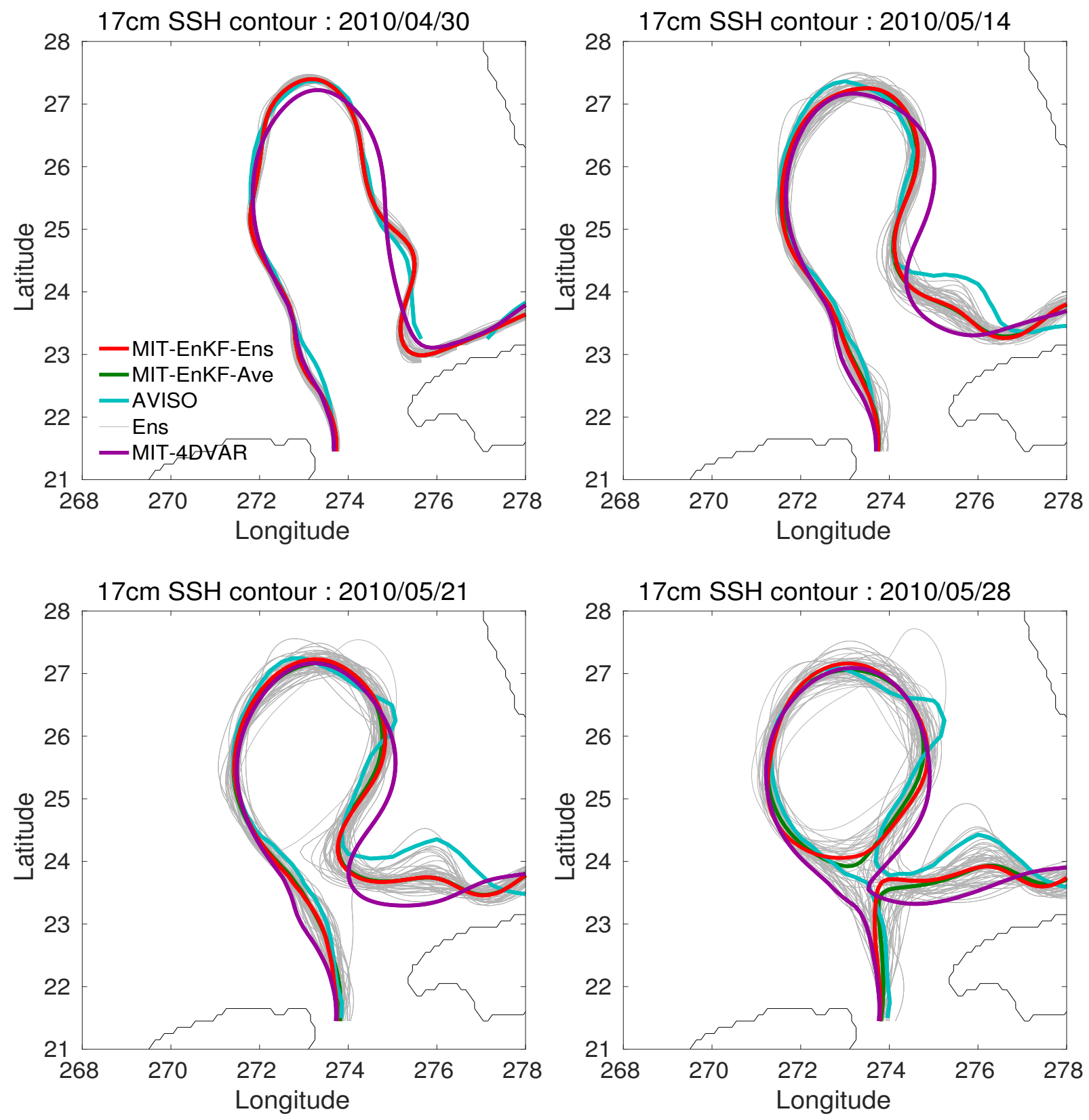

FIG. 9: The evolution of the LC based on $17 \mathrm{~cm} \mathrm{SSH}$ contour for the days 1, 14, 21, and 28 of the two-month ensemble forecasts. The gray curves (Ens) show ensemble members, the red curve (MIT-EnKF-Ens) shows forecast initialized using ensemble mean analysis, the green curve (MITEnKF-Ave) shows the mean of the ensemble forecast, and the cyan curve shows AVISO analysis. The MITgcm-DART EnKF assimilation used filter parameters of EnKF2010-N50-I1.2-L250 (refer Table 4). 

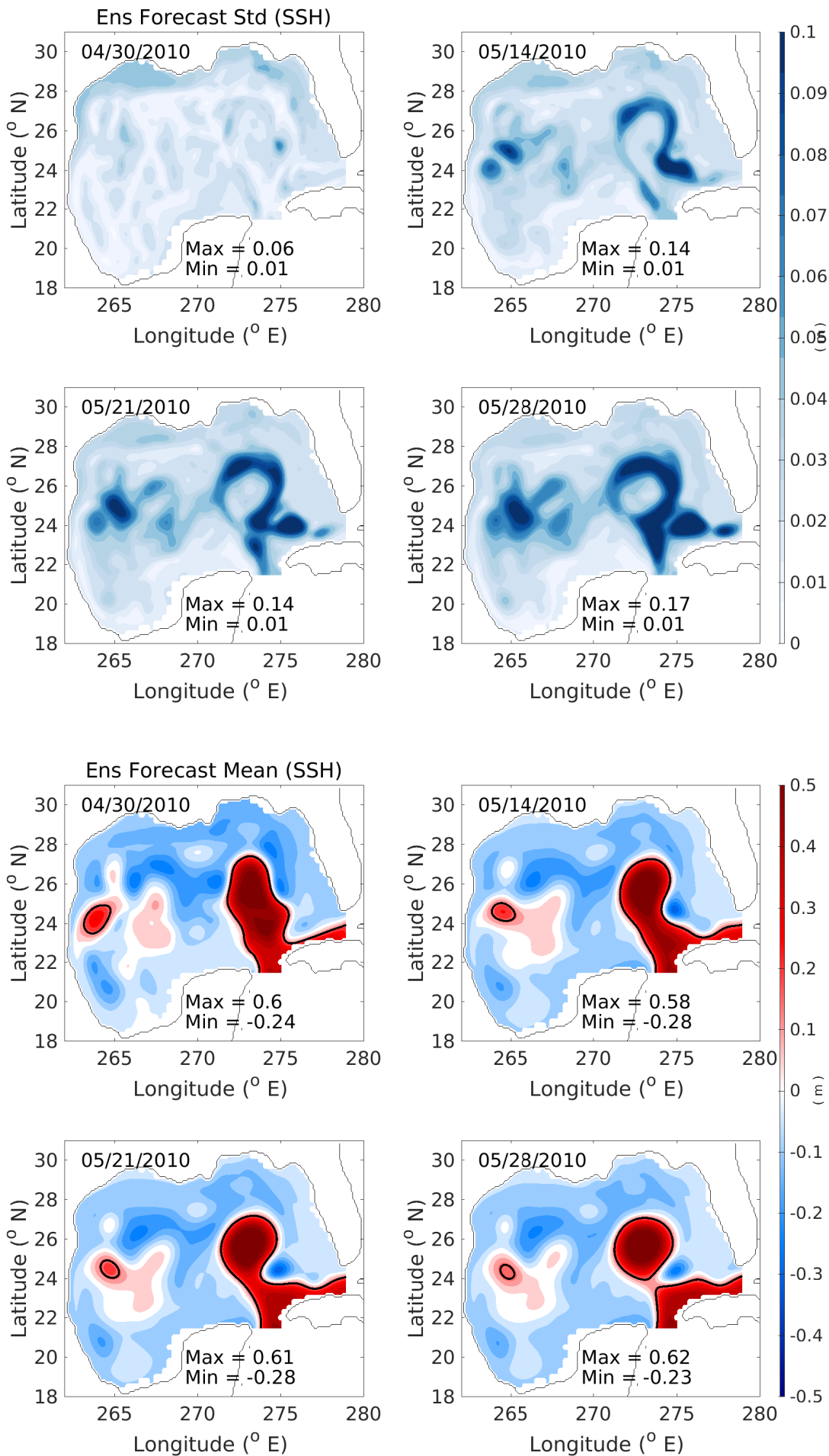

FIG. 10: SSH standard deviation (top four panels) and mean (bottom four panels) for the days 1, 14, 21, and 28 of the two-month ensemble forecasts. The MITgcm-DART EnKF assimilation used filter parameters of EnKF2010-N50-I1.2-L250 (refer Table 4). 

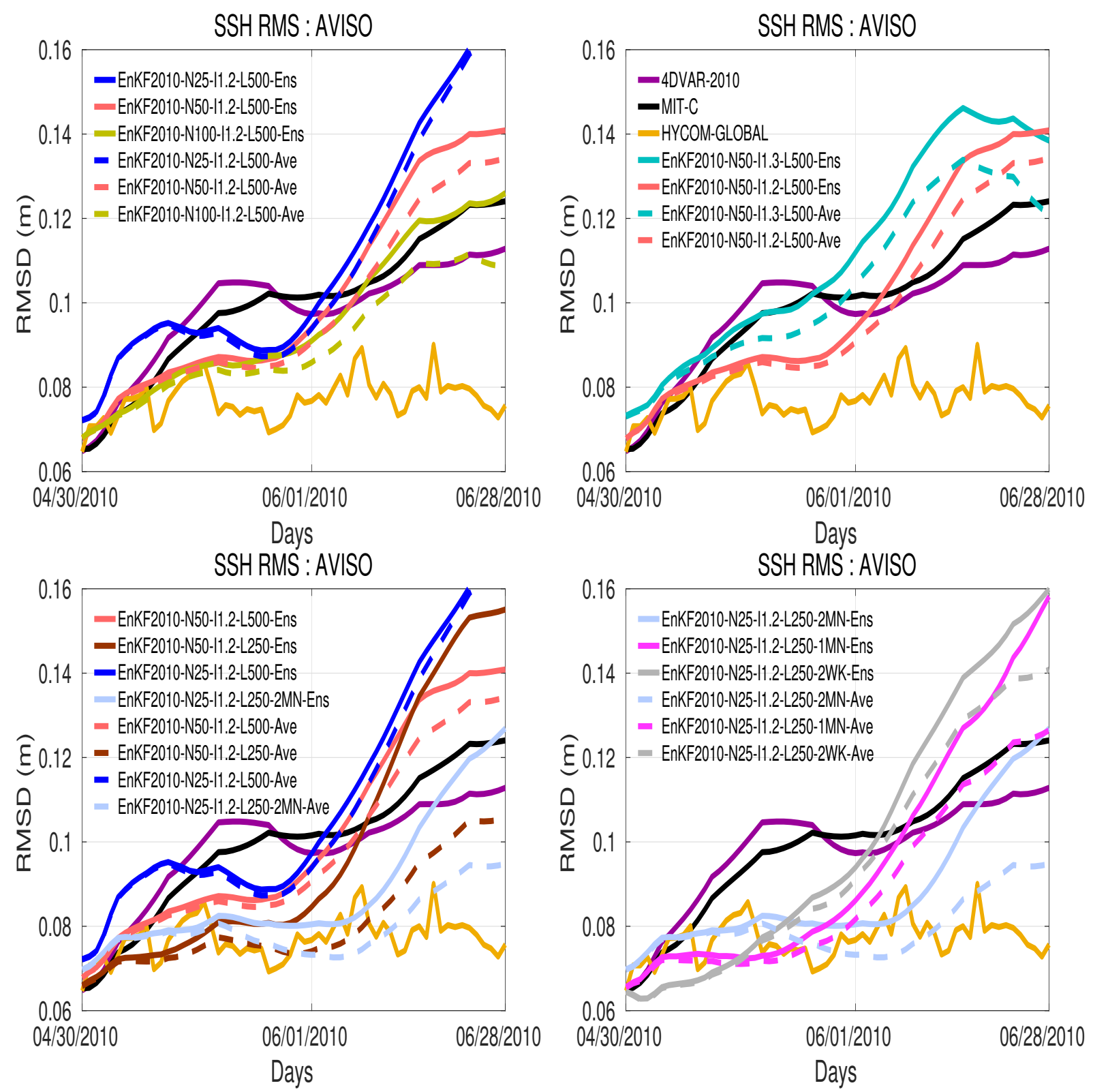

FIG. 11: The MITgcm-DART EnKF filter parameter sensitivity experiments. The top left panel shows sensitivity to ensemble size. The top right panel shows sensitivity to covariance inflation factor. The bottom left panel shows sensitivity to localization length scale. The bottom right panel shows sensitivity to number of assimilation cycles (hindcast period). The MITgcm-DART EnKF and MITgcm-ECCO 4DVAR experiments are summarized in Table 4 and Table 5, respectively. 

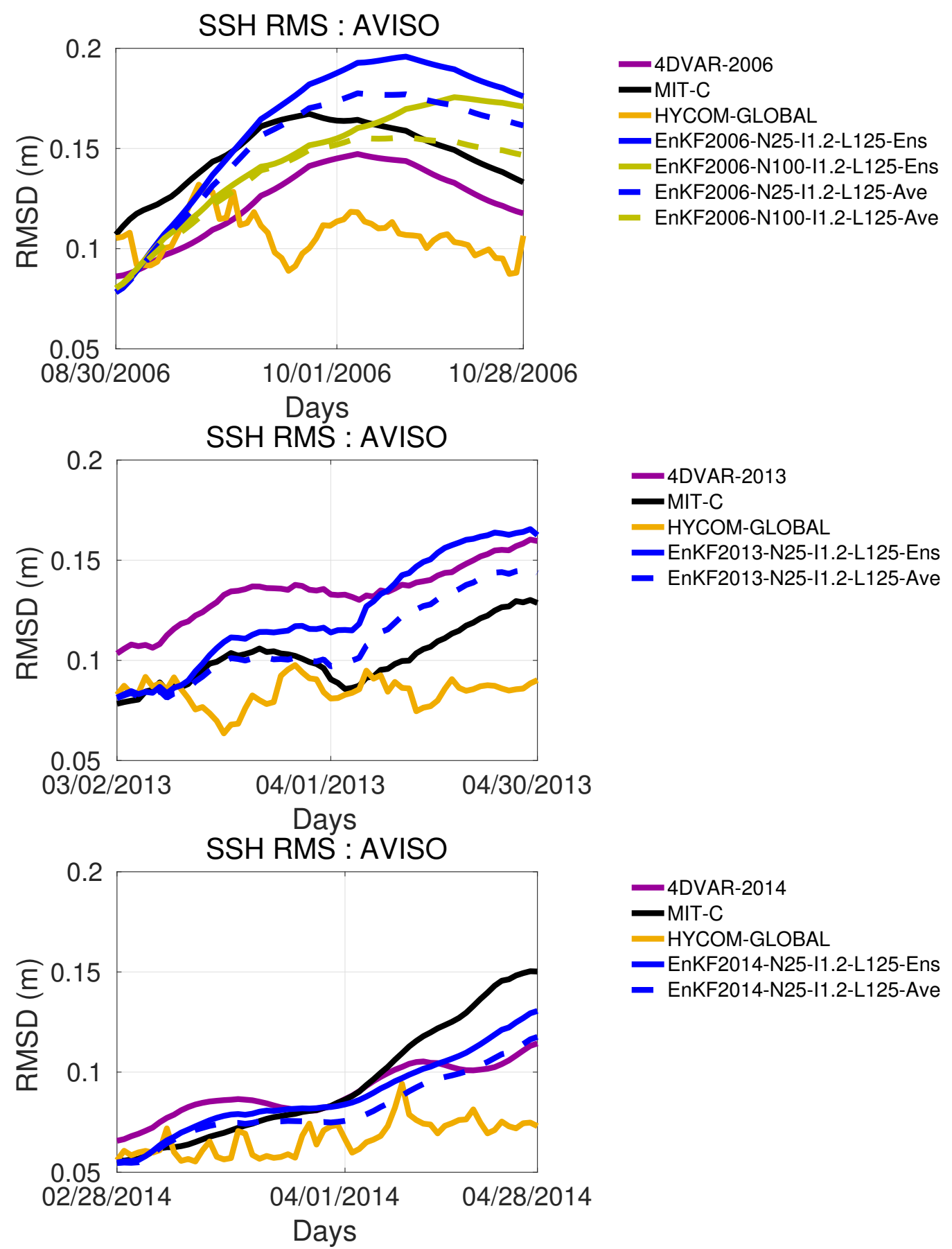

FIG. 12: SSH rmsd with respect to AVISO analysis for MITgcm-ECCO and MITgcm-DART hindcast and forecast experiments for 2006 (top panel), 2013 (middle panel), and 2014 (bottom panel). The golden curve shows HYCOM-GLOBAL analysis, purple curve shows the forecast from MITgcm-ECCO optimized state (MIT-4DVAR), and black curve (MIT-C) shows the control forecast initialized using HYCOM/NCODA global daily analysis for the forecast start date. The blue and green curves shows forecast from ensemble mean analysis, with and their respective means of ensemble forecasts marked by dashed curves. The MITgcm-DART EnKF and MITgcmECCO 4DVAR experiments are summarized in Table 4 and Table 5, respectively. 